\title{
Rimak International Journal of Humanities and Social Sciences
}

ISSN: 2717- 8293

Bousalham AISSAT 1

\section{MOROCCAN PARLIAMENTARY HISTORY 1963-2016: \\ A STUDY OF THE STRUCTURE AND DEVELOPMENT OF THE CONSTITUTIONAL POWERS OF PARLIAMENT}

http://dx. doi. org/10. 47832/2717-8293. 2-3.13

\section{Research Article}

Received:

10/12/2020

Accepted:

04/01/2021

Published:

01/02/2021

This article has been scanned by iThenticat No plagiarism detected

\section{Copyright (C) Published} by Rimak Journal, www.rimakjournal.com

Rimar Academy, Fatih, Istanbul, 34093 Turkey

All rights reserved

\section{Abstract:}

This study attempts to provide a legal reading in the composition of the Moroccan Parliament in light of the transformation of the contents of the constitutional history of the Kingdom of Morocco from 1963 to the year 2011, as it will focus on the organizational transformations that the first chamber of the Moroccan Parliament defined.

Therefore, we will try to monitor the various elements of the development of the structure of the Moroccan House of Representatives, through a reading of the Moroccan constitutions and organizational laws, the development of power or the constitutional functions assigned to it, based on the constitutions and internal regulations of the House of Representatives.

Thus, this study constitutes a reference basis for understanding the Moroccan parliamentary history, for the House of Representatives in terms of its structure and the constitutional powers assigned to it.

Key words: The Constitution, Bicameralism, Parliament, Legislative Authority, Representative Practice.

\footnotetext{
${ }^{1}$ Researcher, Mohammed V University, Morocco, aissatstudies2018@ gmail.com, https://orcid.org/0000-0001$\underline{7748-8698}$
} 


\section{التاريخ النيابي المغربي 1963- 2016: دراسة في البنية وتطور السلط الدستورية للبرلمان}

\section{بوسلهام عيسات 2}

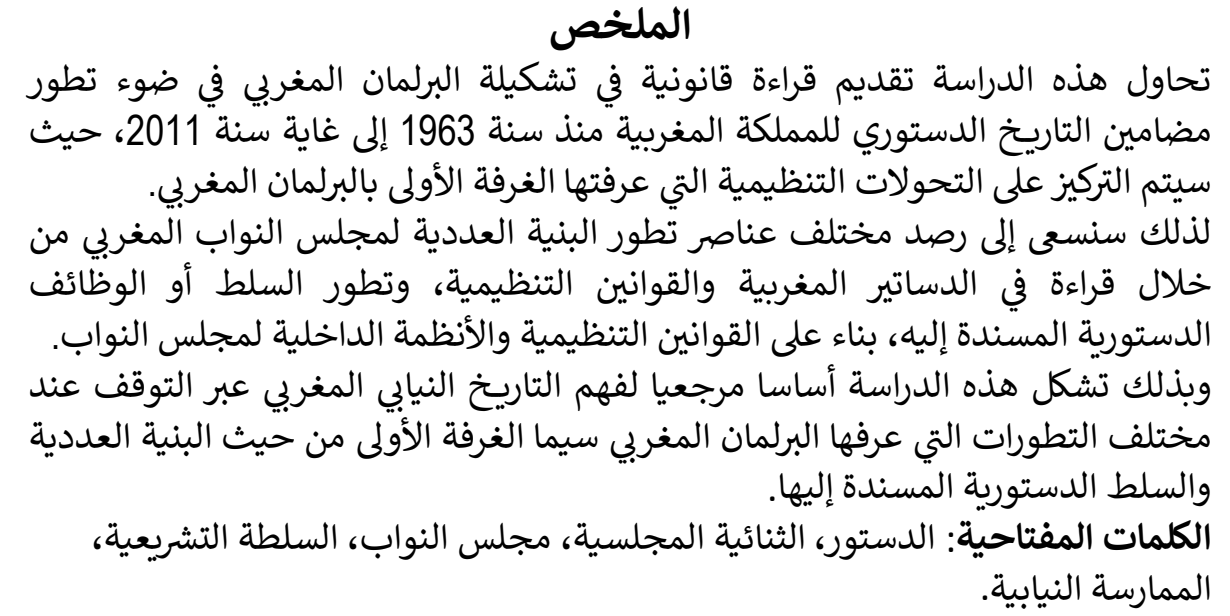

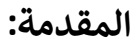

يعتبر البرلمان في الزمن الراهن إحدى المؤسسات السياسية الجوهرية داخل أي نظام سياسي ديمقراطي، لكونه الجهاز الذي يعكس مشاركة المواطنات والمواطنين في تدبير شؤونهم العامة عبر ممثليهم الذين ينتخبونهم عن طريق التيق الاقيتراع

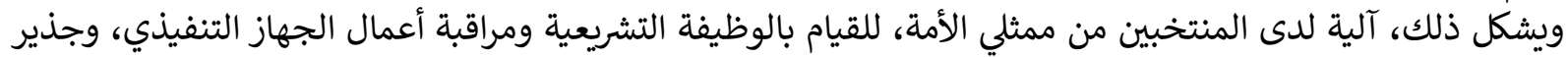

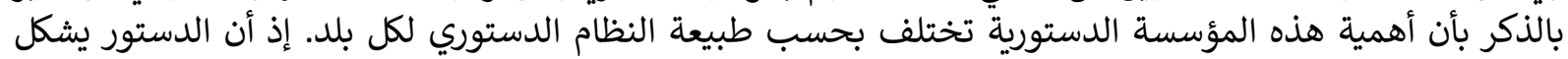

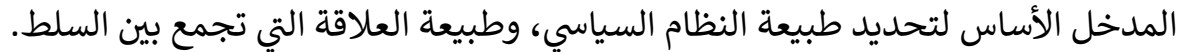

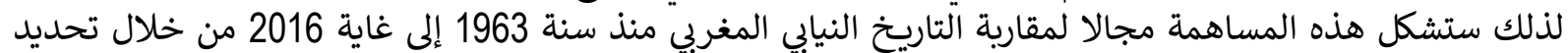

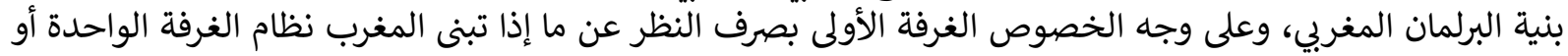

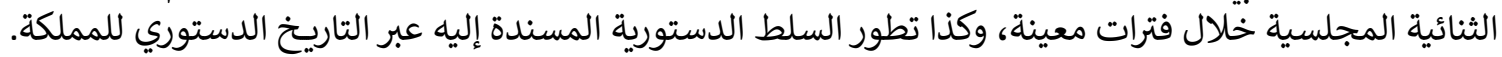

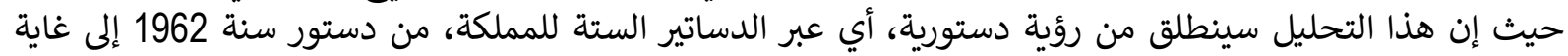

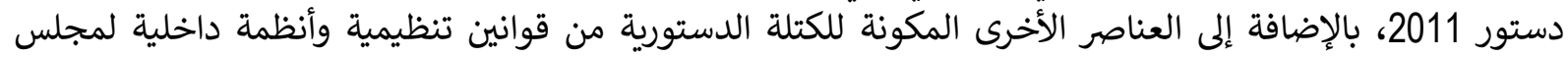

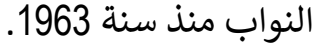
ومنه، فإن مخرجات هذه الدراسة ستحاول الانطلاق من تساؤل إشكالي محوري كالتالي:

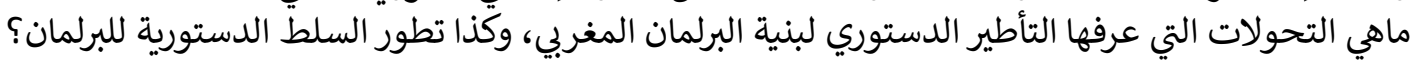
ومن تم سيتم معالجة هذه الدراسة التئ عبر المحورين التاليين:

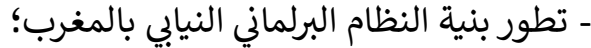
- تطور السلط الدستورية للبرلمان.

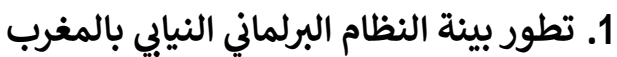

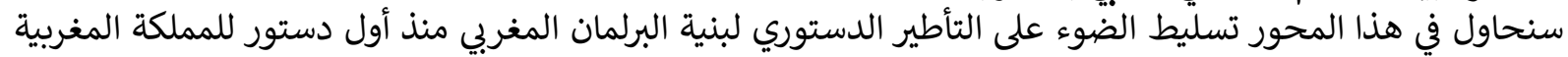

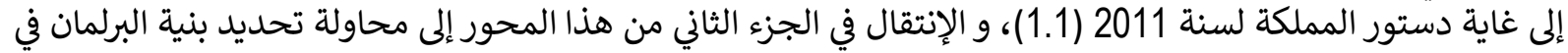

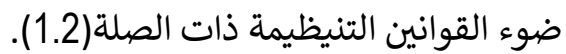

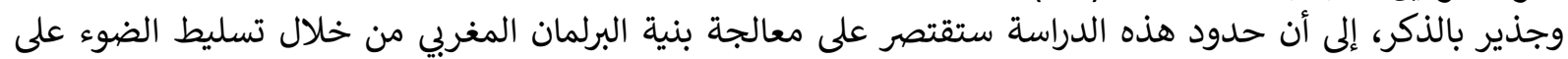

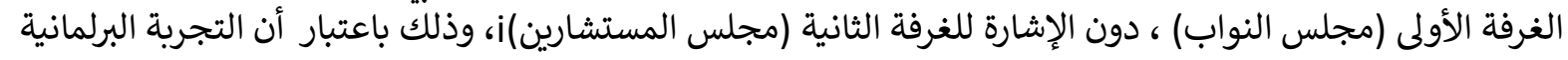


المغربية عبر التاريخ الدستوري قد عملت على تبني نظام الثنائية المجلسية في دساتير (1962-1972-1996-2011) و نظام

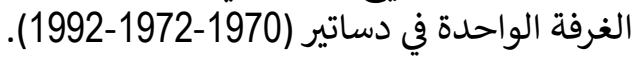

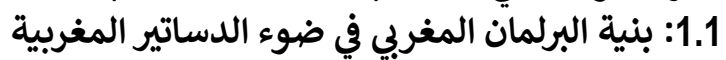

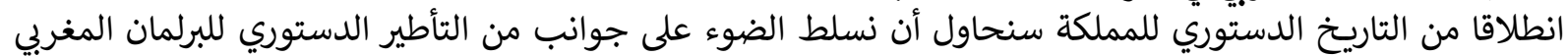

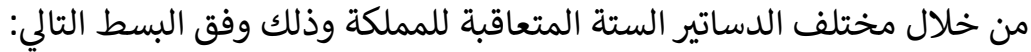

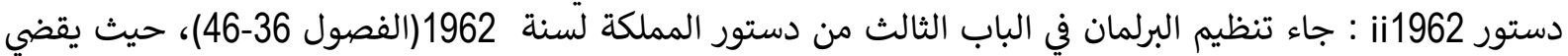

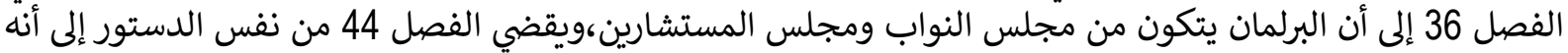

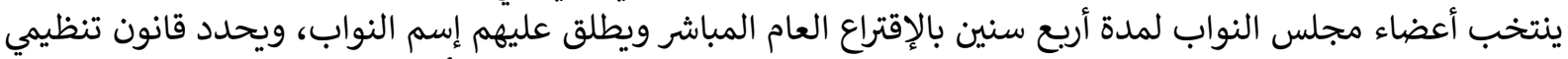

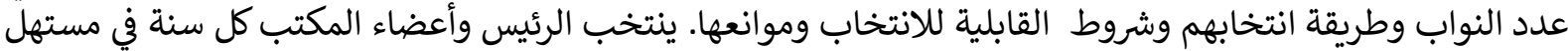

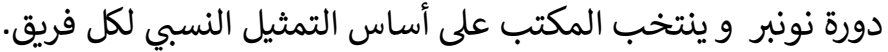

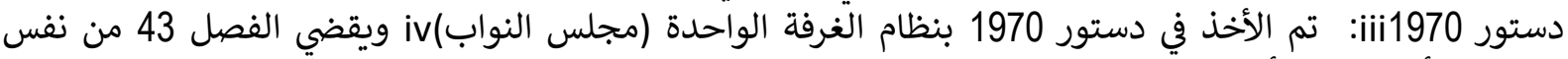

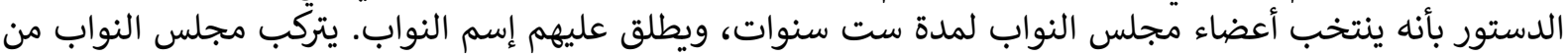

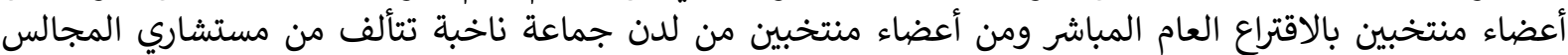

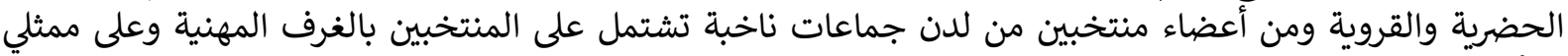

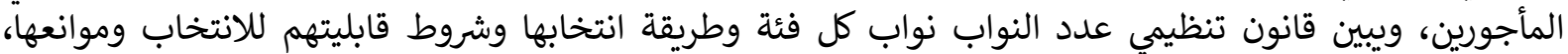

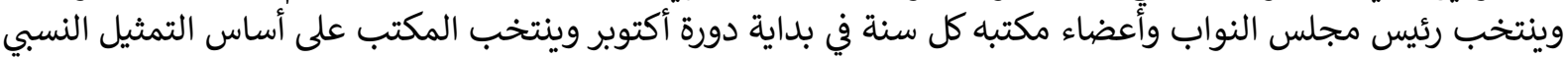
لكل فريق.

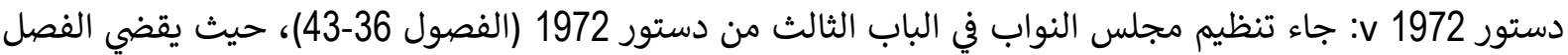

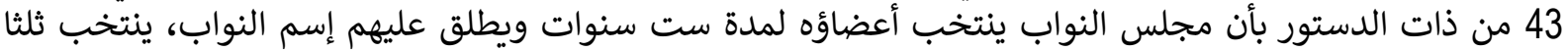

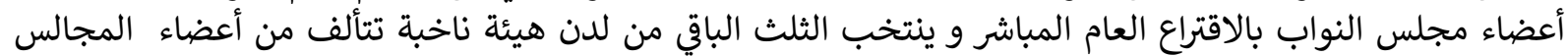

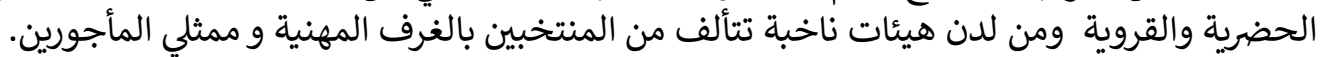

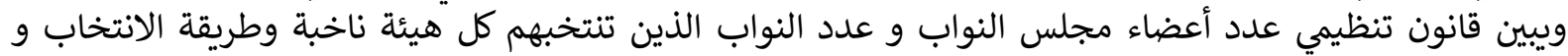
شروط القابلية للانتخاب و وأحوال التنافي.

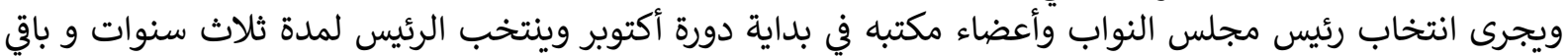

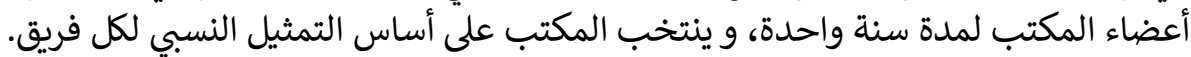

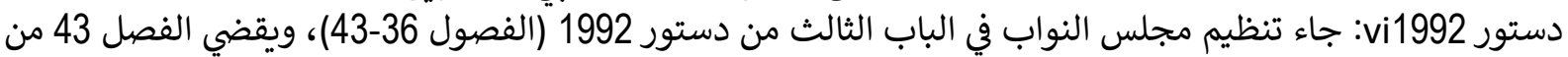

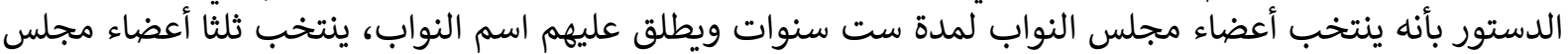

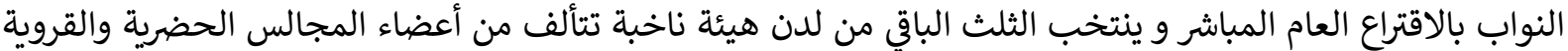

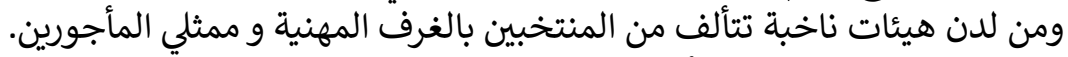

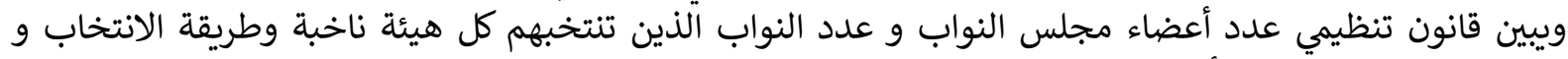
شروط القابلية للانتخاب و أحوال التنافي. وينتخب مجلس النواب رئيسه لمدة ثلاث سنواتئ التئ وينتخب أعضاء مكتبه لمدة سنة على أساس التمثيل النسبي لكل فريق.

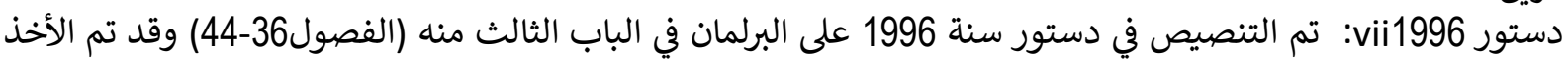

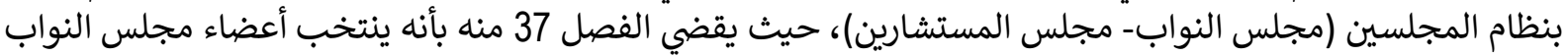

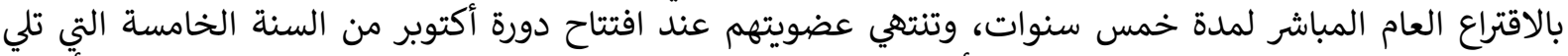

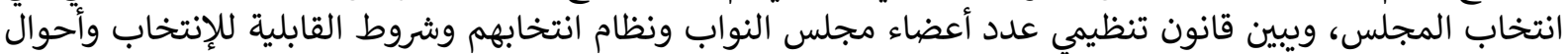
التنافي ونظام المنازعات الانتخابية. وينتخب رئيس مجلس المنائ النواب أولابل في مستهل الفترة النيابية ثم في دورة أبريل للسنة الثالثة من هذه الفترة، وذلك لما

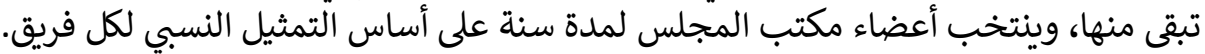

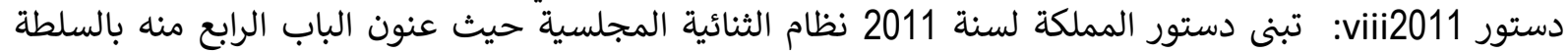

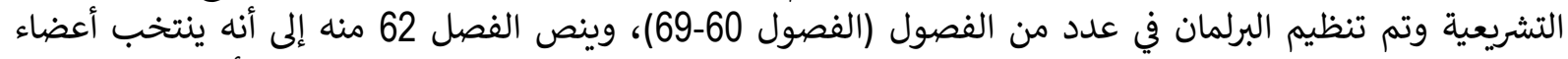

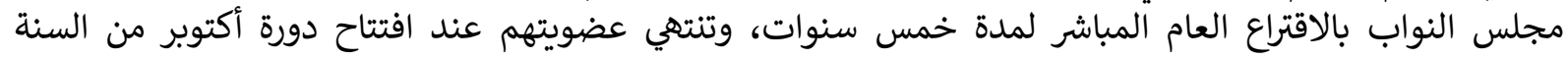

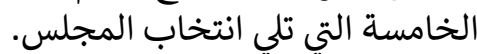

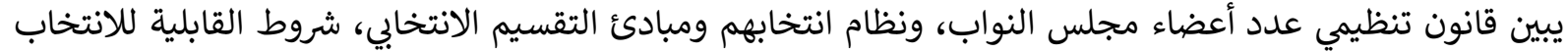
وحالات التنافي و قواعد الحد من الجمع بين الانتدابات ونظام النظام النغازعات وميادئ الانتخابية. 


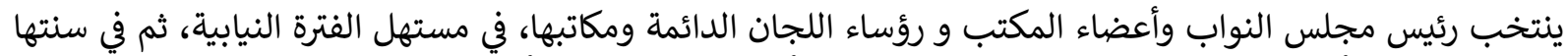

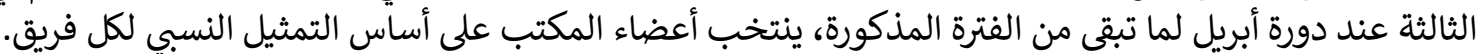

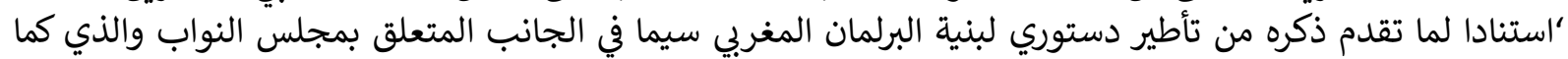

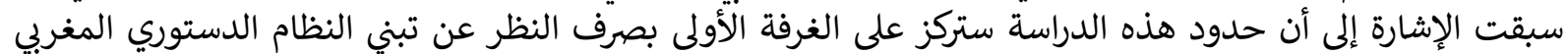

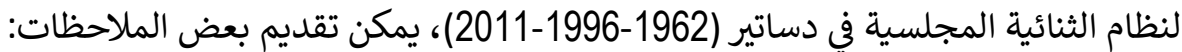

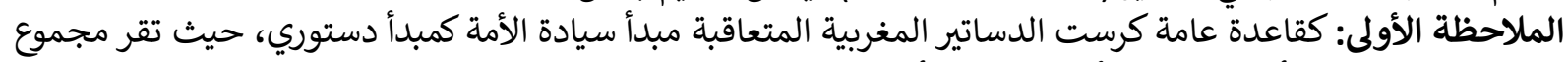

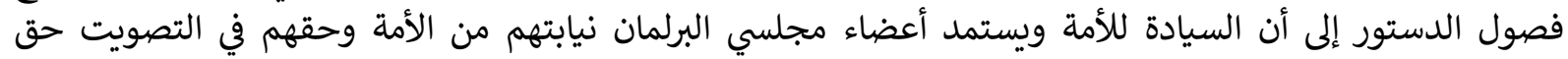

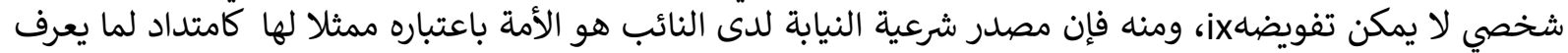

بالديمقراطية التمثيلية.

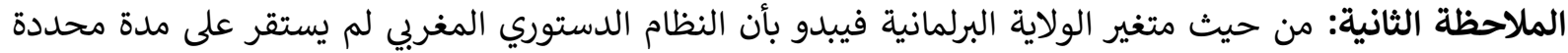

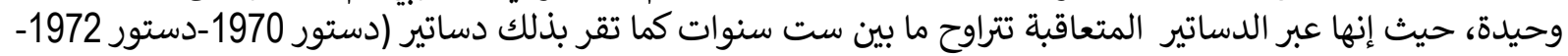

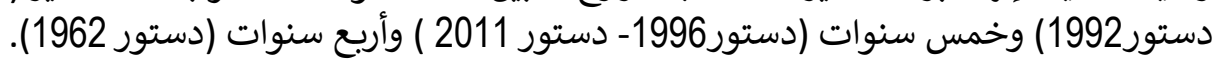

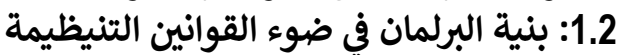

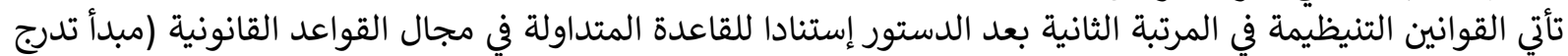

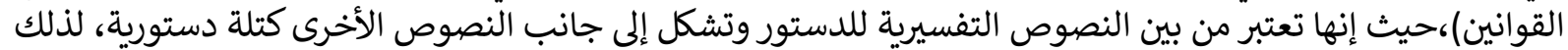

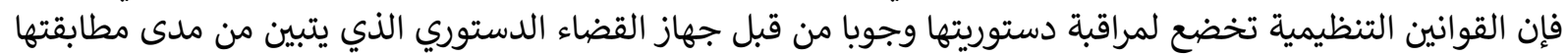

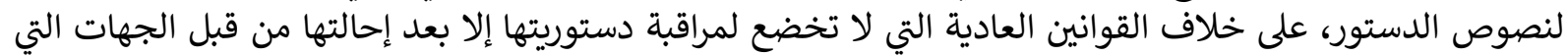

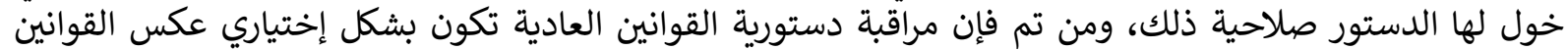

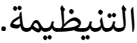

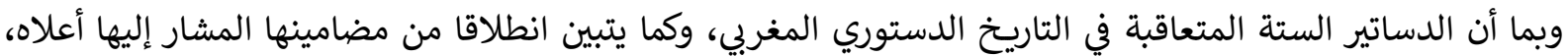

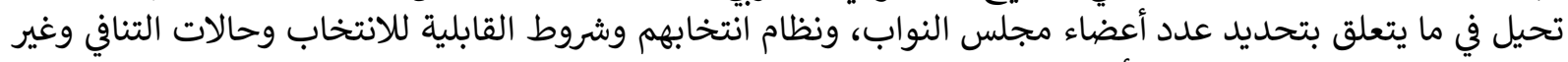

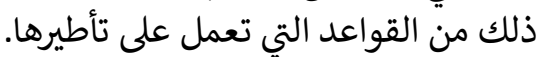

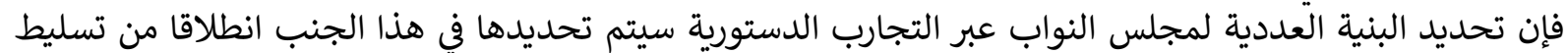

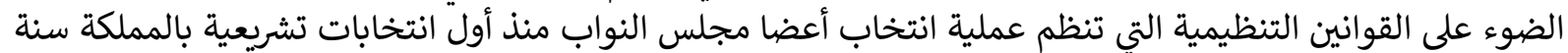

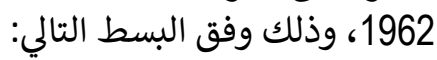

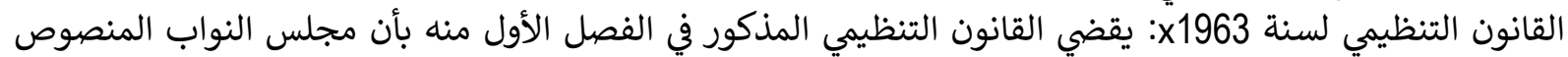

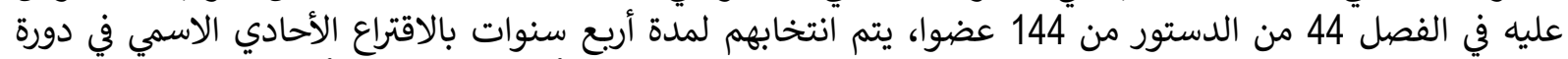

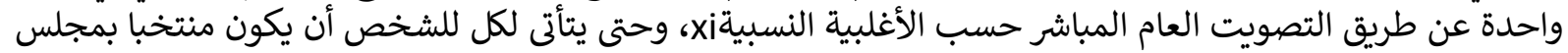

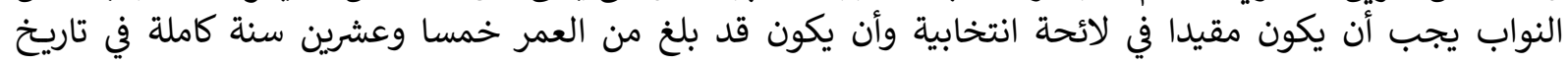

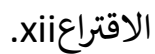

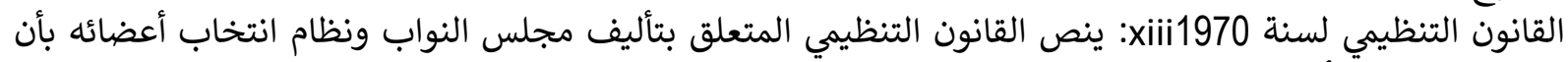

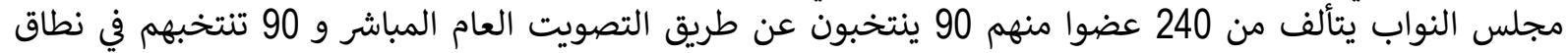

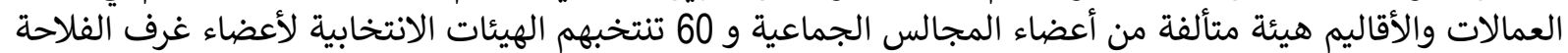

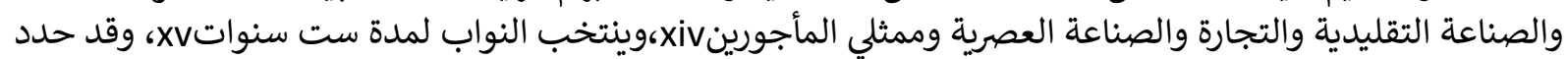

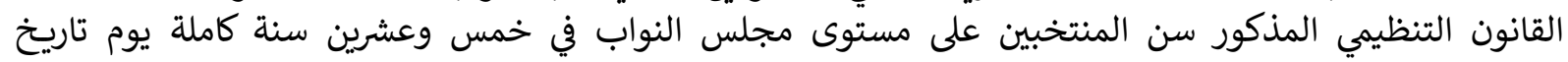

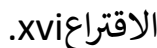

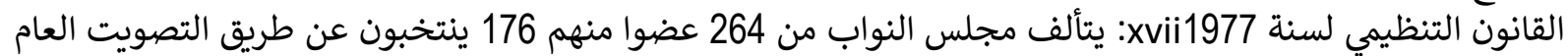

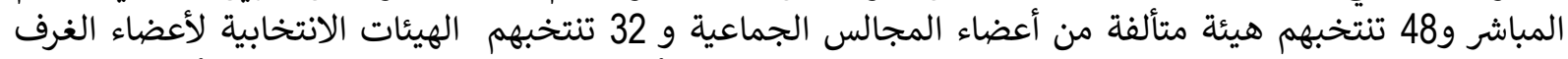

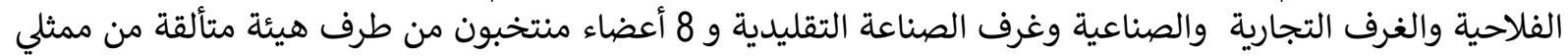

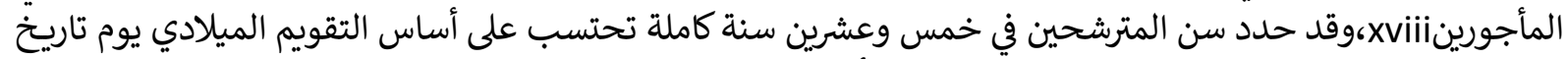

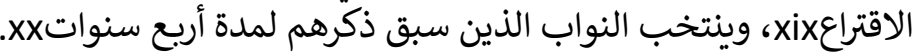

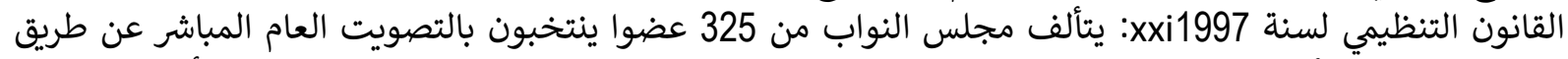

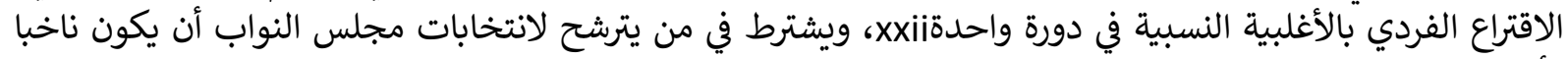

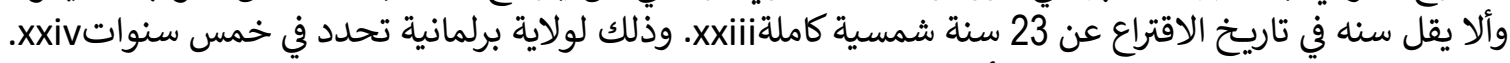

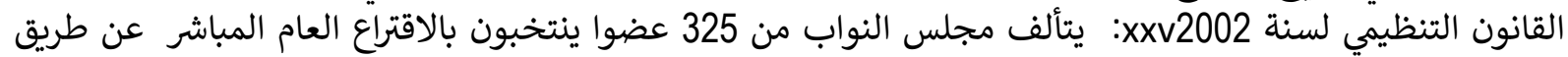

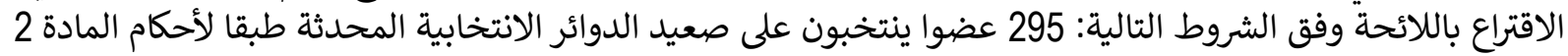


من القانون التنظيمي؛ 30 عضوا ينتخبون على الصعيد الوطني؛ يجرى الانتخاب بالتمثيل النسبي حسب قاعبي إعدة أكبر بقية

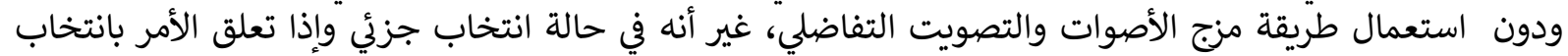

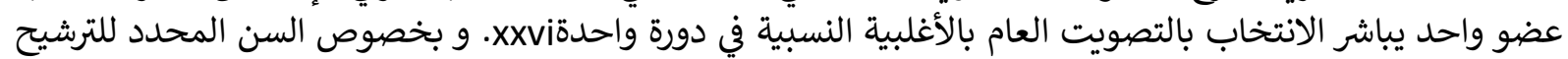

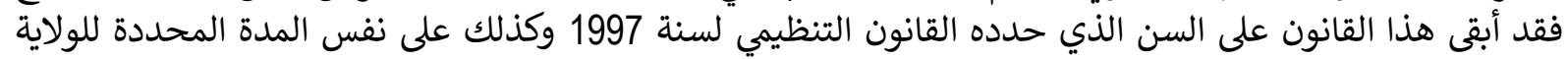

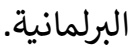

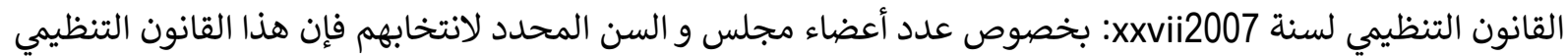

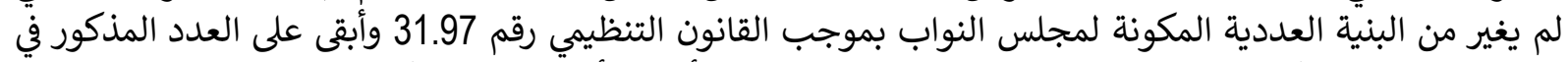

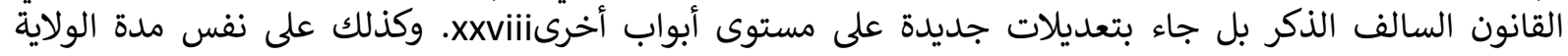
xxix المحددة بموجب الدستون

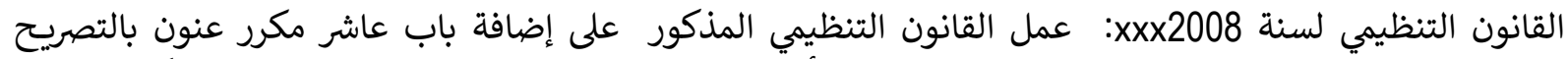

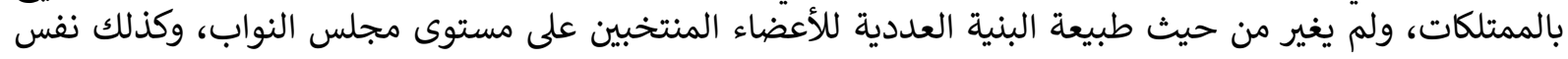

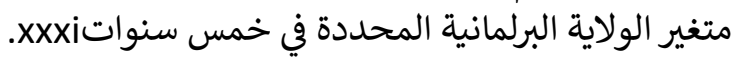

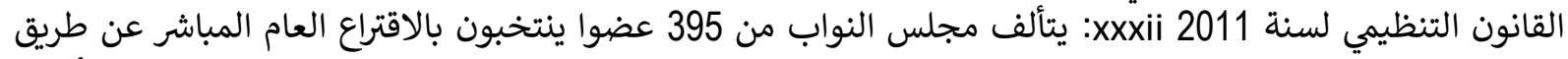

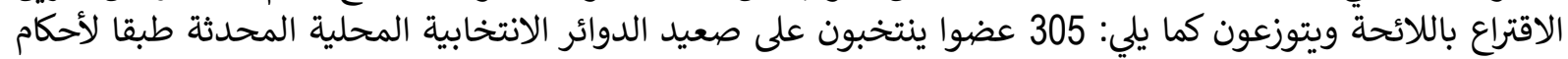

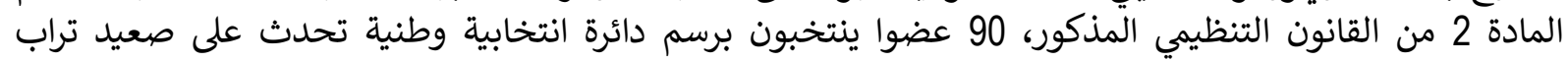

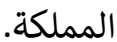

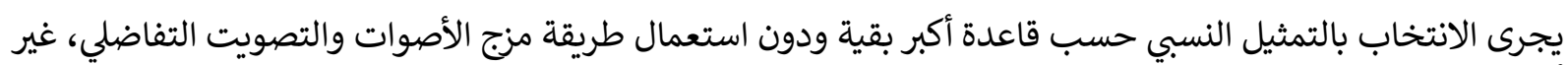

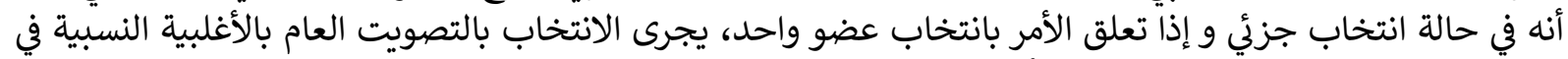

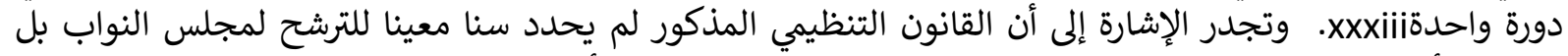

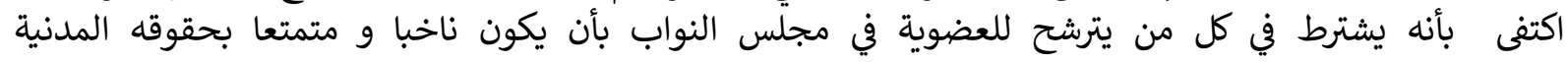

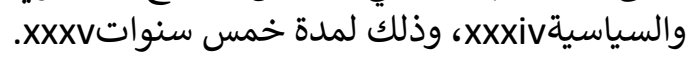

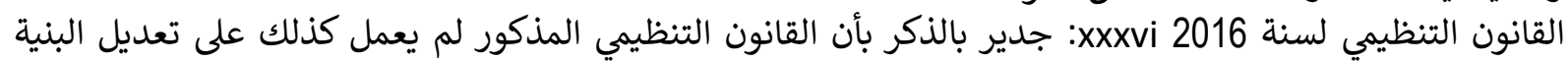

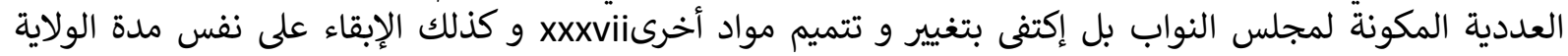
المحددة بموجب الدستور.

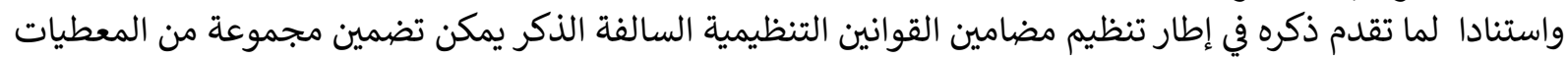

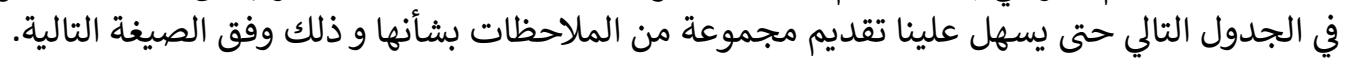


الجدول رقم 1 : تحديد البنية العددية لأعضاء مجلس النواب ونظام انتخابهم منذ 1963

\begin{tabular}{|c|c|c|c|c|c|}
\hline 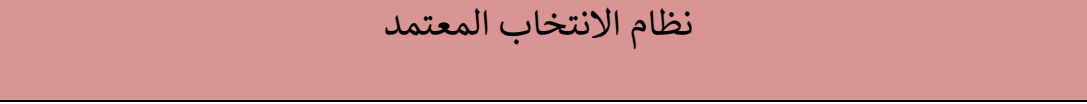 & 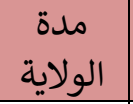 & 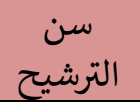 & \multicolumn{2}{|c|}{ 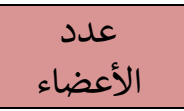 } & 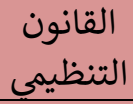 \\
\hline الاقتراع الأحادي الاسمي في دورة واحدة عن طريق التصويت العام المباشر النبية & 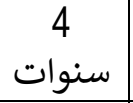 & 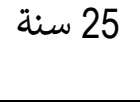 & \multicolumn{2}{|c|}{144} & 1963 \\
\hline التصويت العام المباشر & \multirow{3}{*}{ 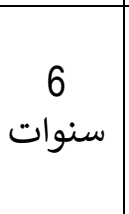 } & \multirow{3}{*}{ 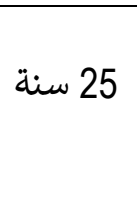 } & 90 & \multirow{3}{*}{240} & \multirow{3}{*}{1970} \\
\hline تنتخبهم في نطاق العمالات و الأقاليم هيئة متألفة من أعضاء المجالس الجماعية & & & 90 & & \\
\hline 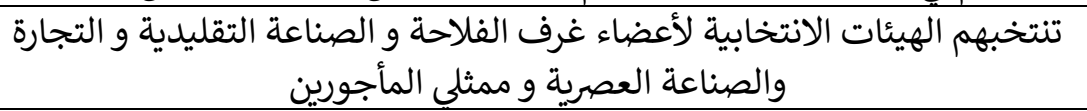 & & & 60 & & \\
\hline التصويت العام المباشر & \multirow{4}{*}{ 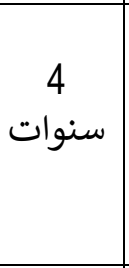 } & \multirow{4}{*}{ 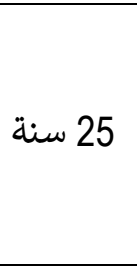 } & 176 & \multirow{4}{*}{264} & \multirow{4}{*}{1977} \\
\hline تنتخبهم هيئة متألفة من أعضاء المجالس الجماعية & & & 48 & & \\
\hline تنتخبهم الهيئات الانتخابية لأعضاء الغرف الفلاحية والغرف التجارية و و الصناعلة التريدية & & & 32 & & \\
\hline أعضاء منتخبون من طرف هيئة متألقة من ممثلى المأجورين & & & 8 & & \\
\hline التصويت العام المباشر عن طريق الاقتراع الفردي بالأغلبية النسبية في دورة & 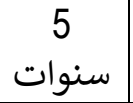 & 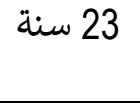 & \multicolumn{2}{|c|}{325} & 1997 \\
\hline 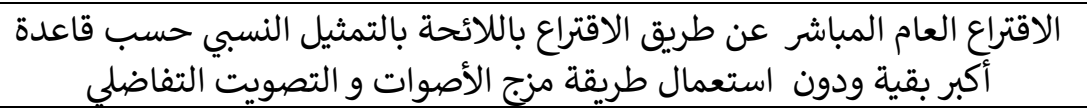 & 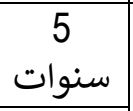 & \multirow[t]{2}{*}{ ( ق إنة } & 295 & 325 & 2002 \\
\hline ينتخبون على الصعيد الوطني & & & 30 & & \\
\hline \multicolumn{5}{|c|}{ الحفاظ على نفس التركيبة الواردة في القانون التنظيمي لسنة 2002} & 2007 \\
\hline \multicolumn{5}{|c|}{ الحفاظ على نفس التركيبة الواردة في القانون التنظيمي لسنة 2002 . } & 2008 \\
\hline 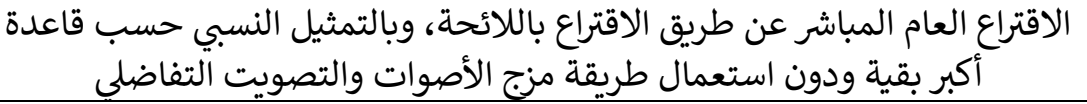 & \multirow[b]{2}{*}{ 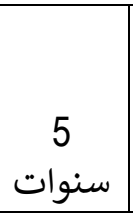 } & \multirow[b]{2}{*}{ 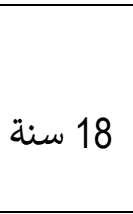 } & 305 & \multirow[t]{2}{*}{395} & 2011 \\
\hline ينتخبون برسم دائرة انتخابية وطنية تحدث على صعيد تراب المملكة & & & 90 & & \\
\hline \multicolumn{5}{|c|}{ الحفاظ على نفس التركيبة الواردة في القانون التنظيمي لسنة 2011} & 2016 \\
\hline
\end{tabular}

بناء على المعطيات الواردة في الجدول التفصيلي رقم (1)، و الذي يحاول أن يبين جانبا من تطور البنية العددية لمجلس

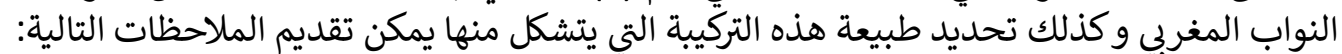

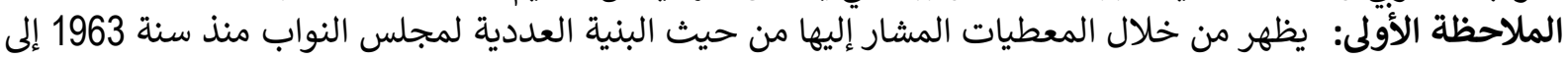

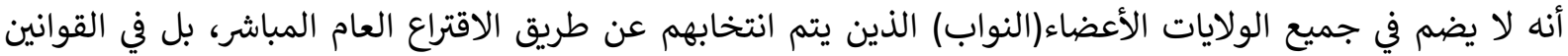

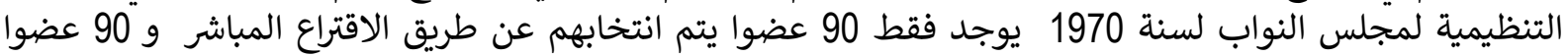

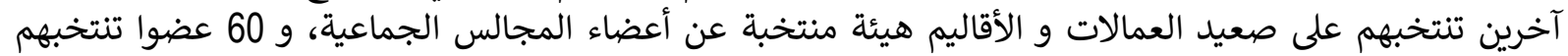

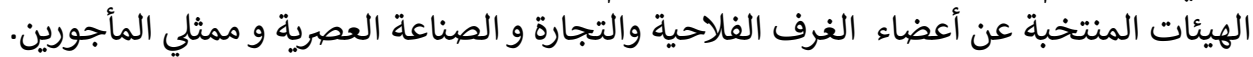

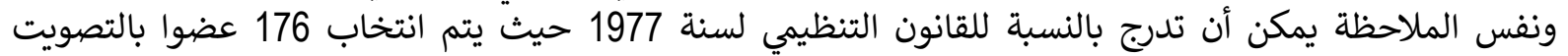

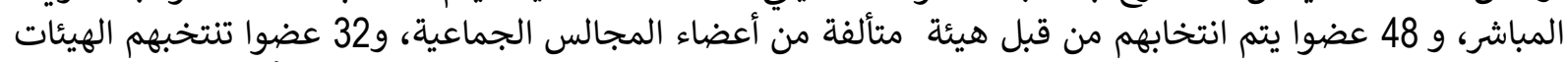

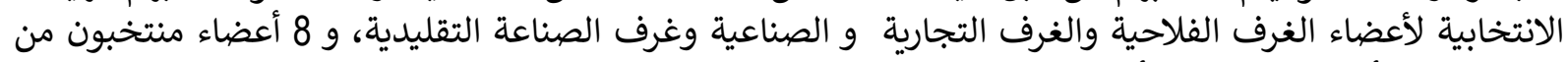
طرف هيئة متألقة من ممثلي المأجورين.

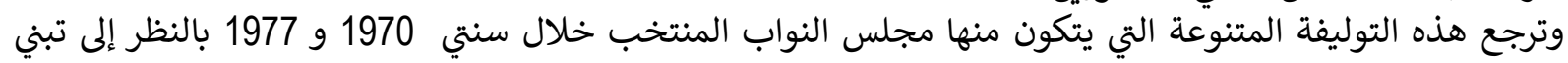

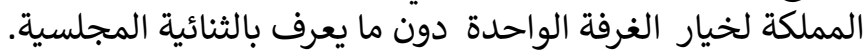

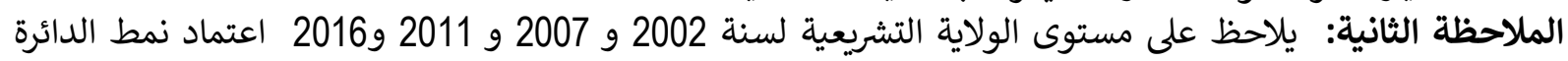
الوطنية، حيث إنه تم انتخاب ثلاثين مقعدا من مجموع المقاعد المخصصة خلانية خلال الولاية التشريعية السابعة والثامنة 


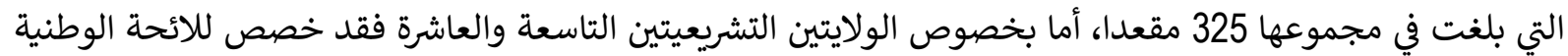
90 مقعدا خصصت منصها 30 مقعدا للشباب من كلا الجنسين البالغين من العمر 40 سنة سنة في تاريخ الاقتراع من أصل 395 مقعدا المكونة لمجلس النواب.

2. تطور السلط الدستورية للبرلمان لمان البـان

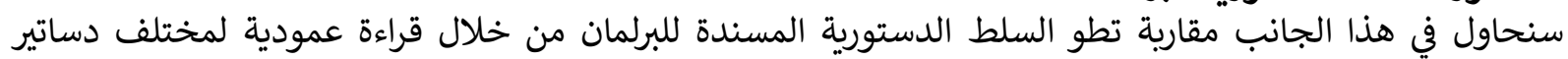

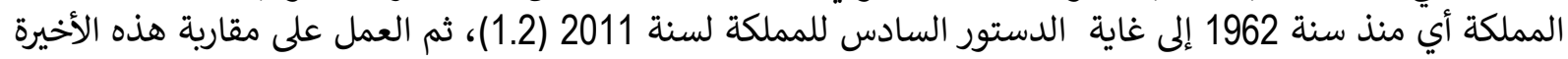

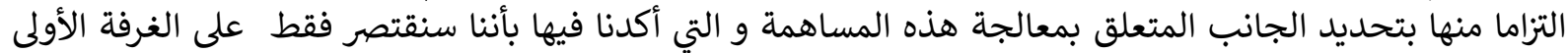

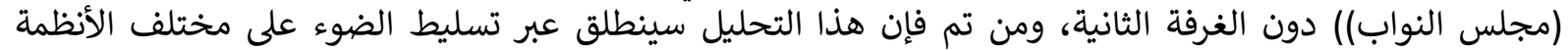

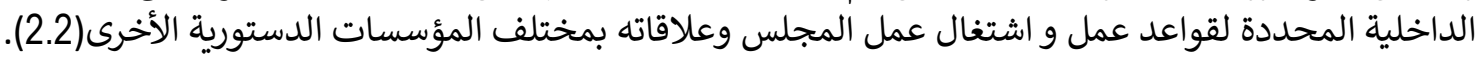

1.2 1.2 سلط البرلمان في الدستورة.

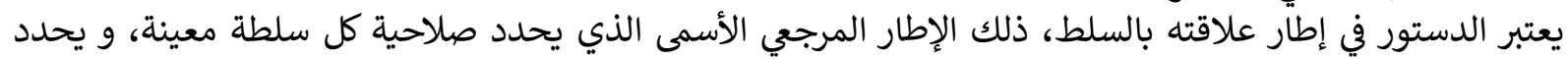

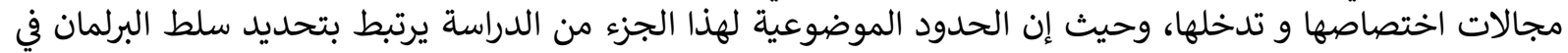

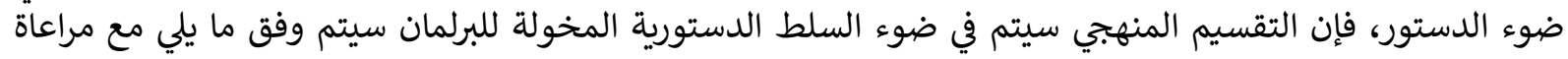

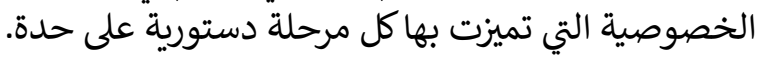

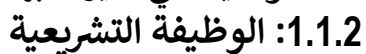

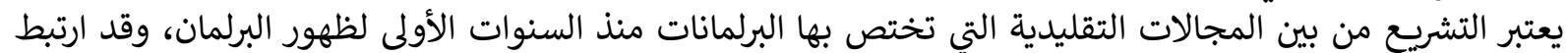

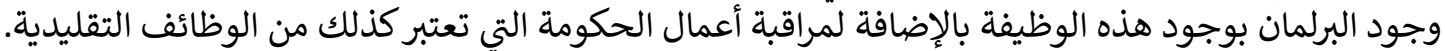

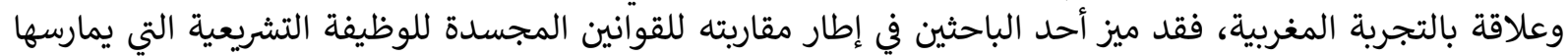

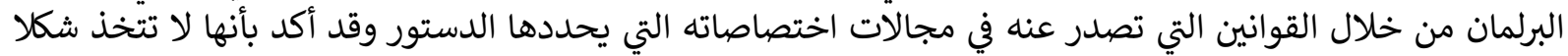

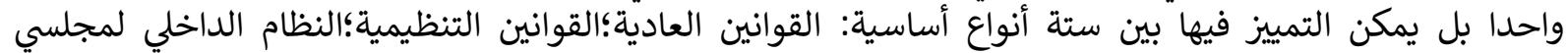

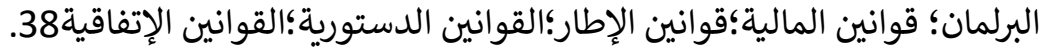

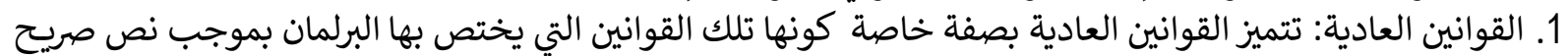

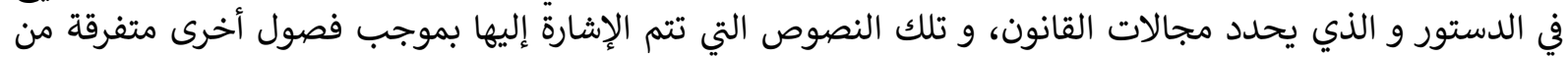

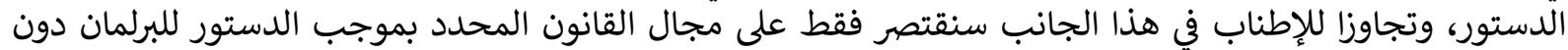

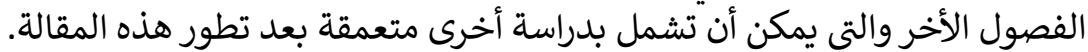

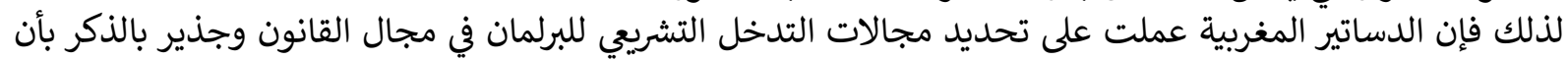

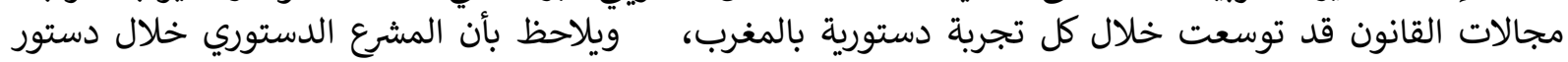

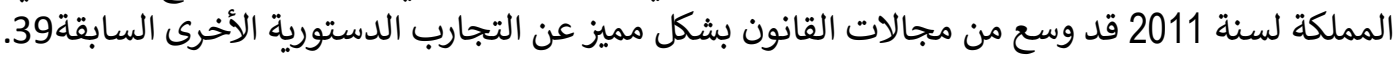

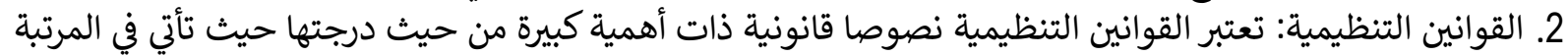

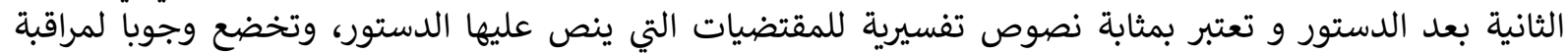

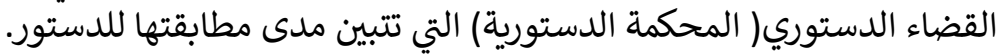

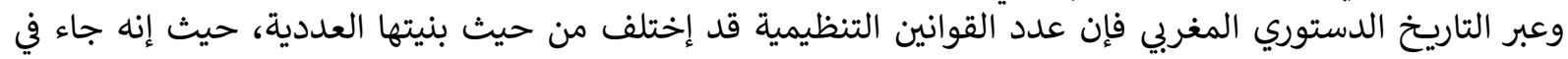

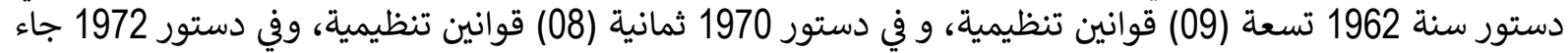
التنصيص على سبعة (07) قوانين تنظيمية، أما بالنسبة لدستون

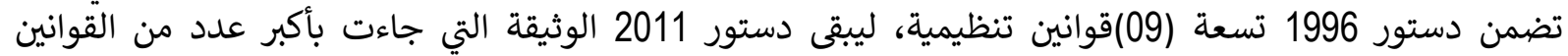

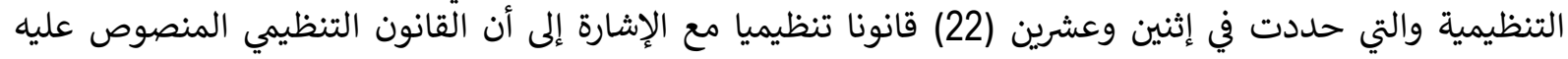

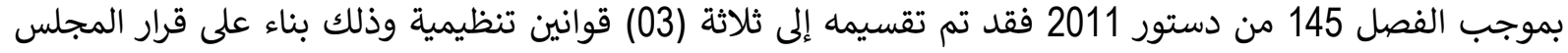

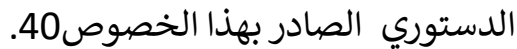

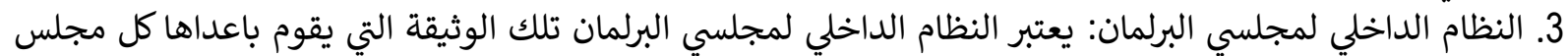

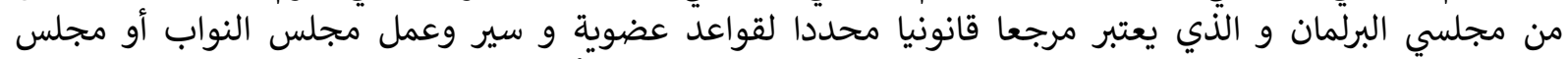

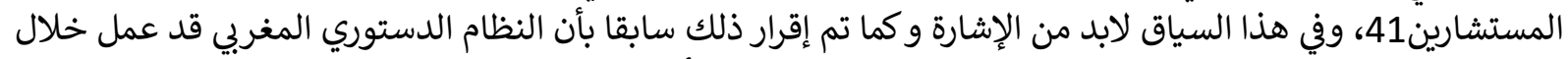

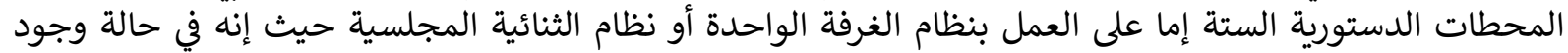

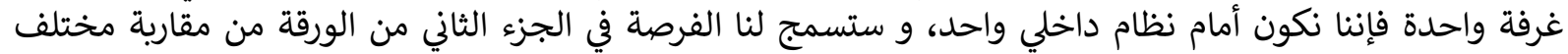

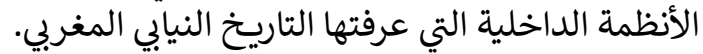

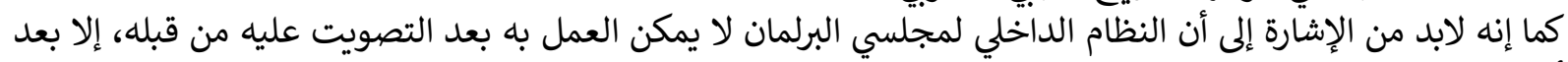

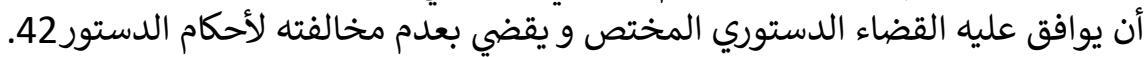


4. قوانين المالية:يعتبر التشريع المالي من بين المجالات التشريعية التي خص بها أيضا البرلمان في المغرب مناب منذ التجرية

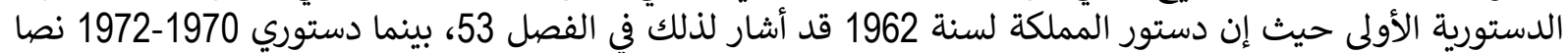
عليه في الفصل 49، ودستور 1992 قد أشار له في الفصل 49، وفي الفصل الفي 50 بموجب دستور 1996، بينما دستور 2011

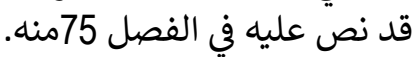

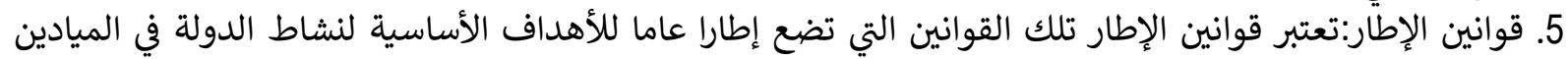

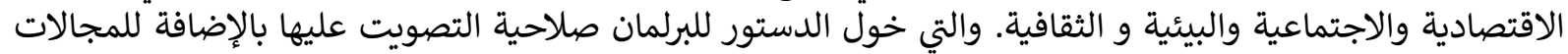

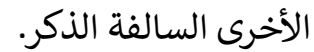
وبخصوص قوانين الإطار فحري بالذكر إلى أن دستور 1962 و 1970 و 1972 والا ينصان عليها، ومن ثمة فهي آلية

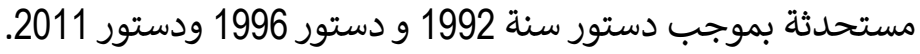

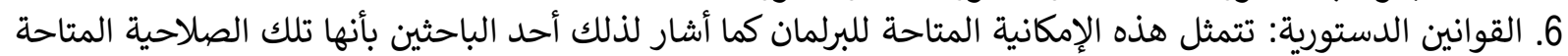

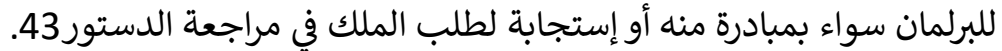

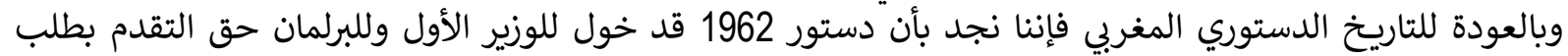

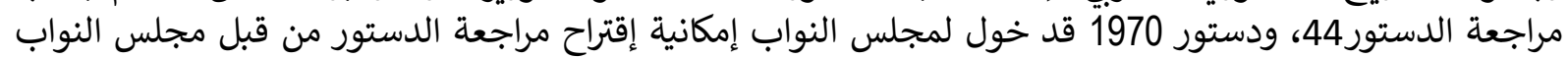

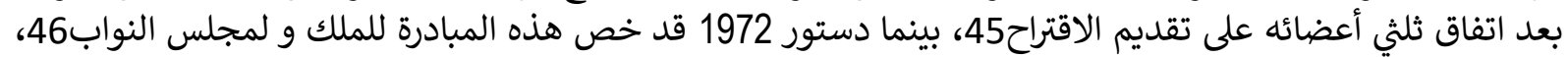

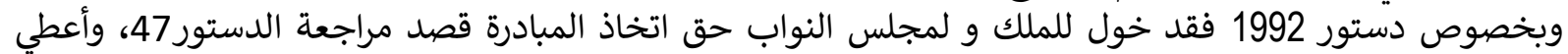

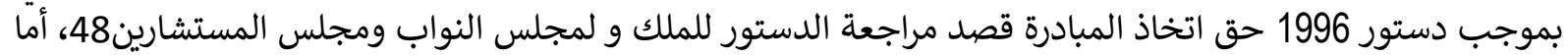

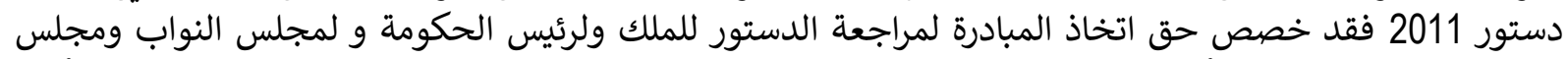

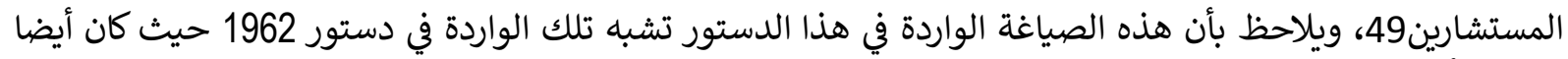

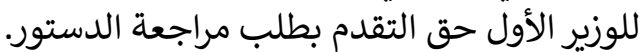

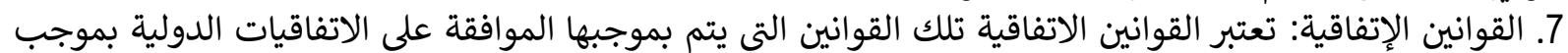

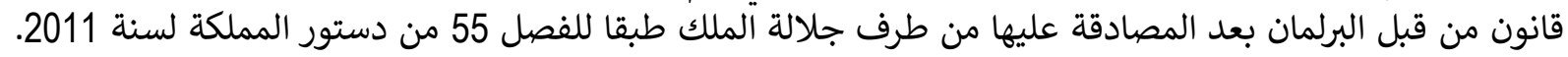

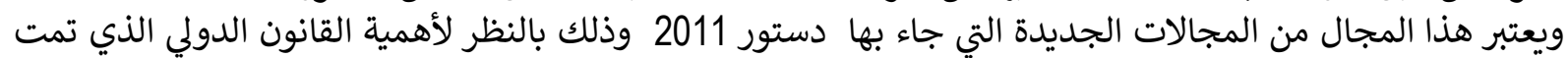

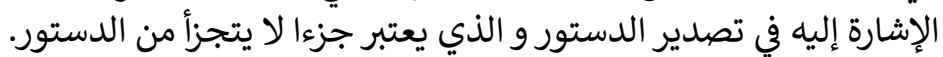

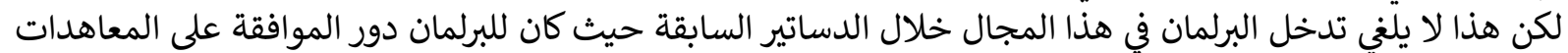

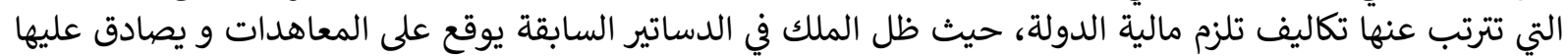

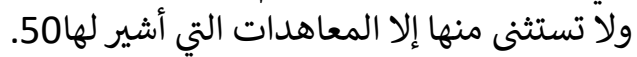

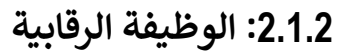

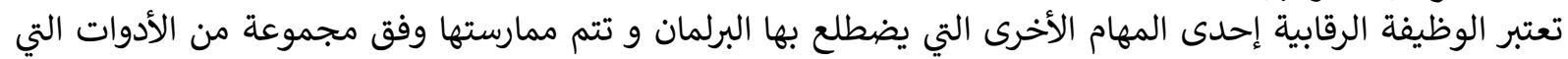

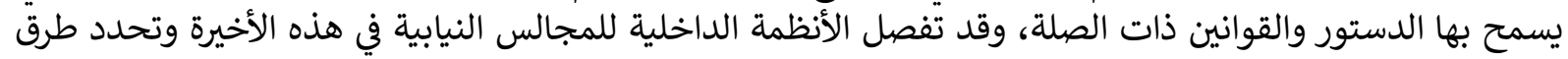

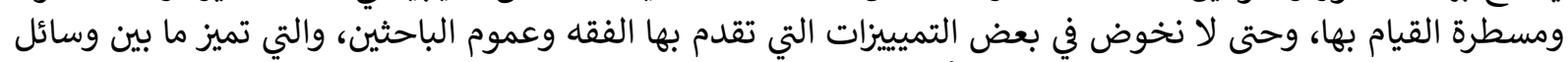

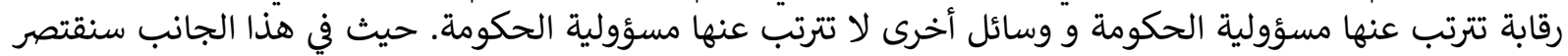

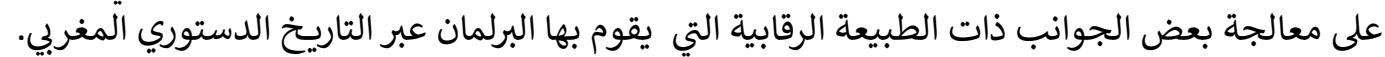

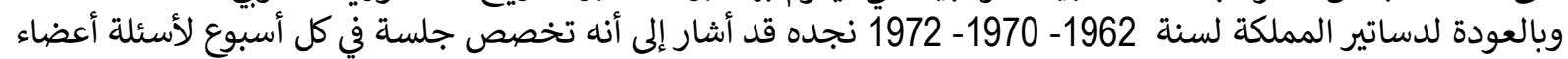

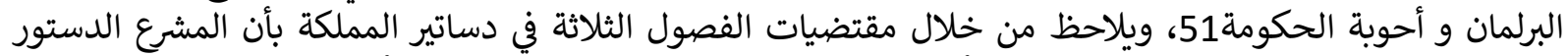

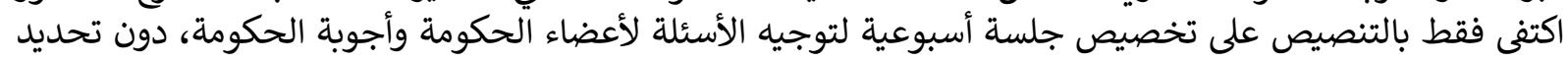

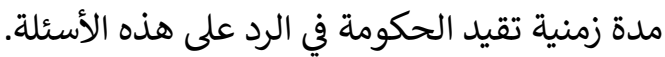

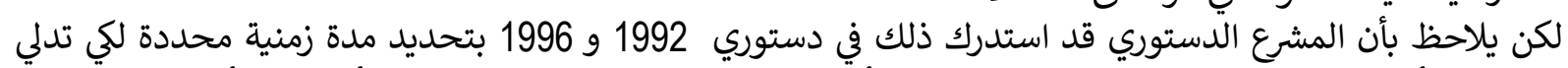

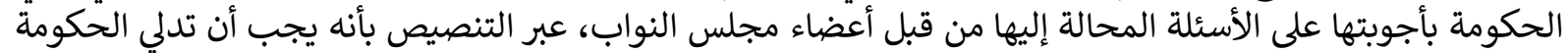

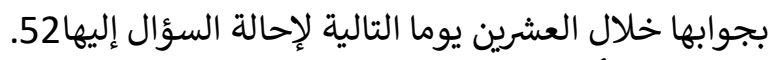

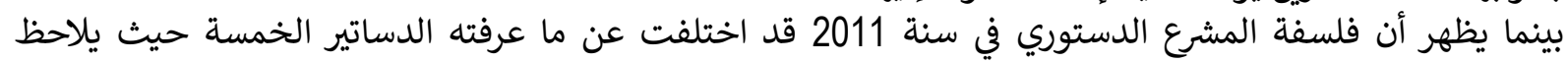

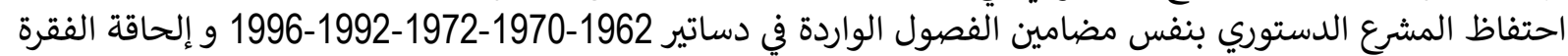

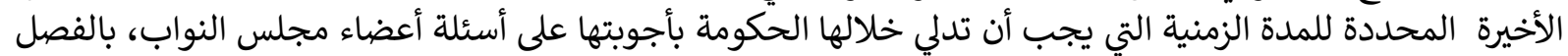

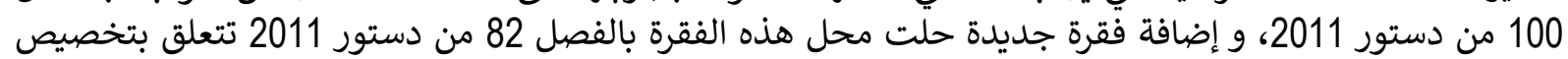

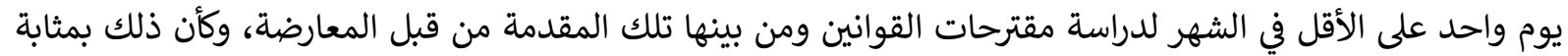

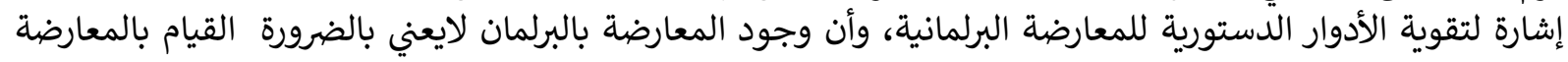


السياسية تجاه الحكومة، بل إن هذه الأخيرة عليها أن تضطلع بكامل أدوارها الدستورية تشريعا ومقارية ودبلوماسية

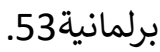

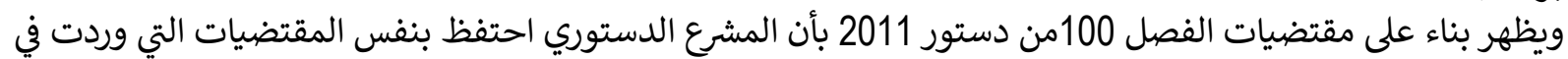

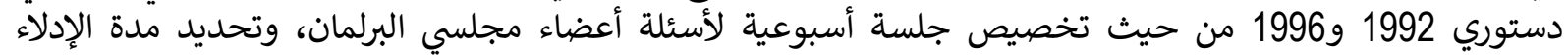

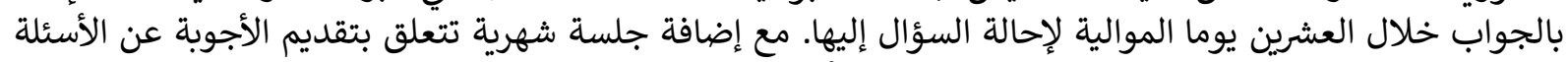

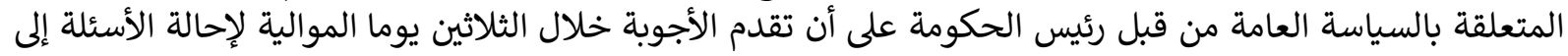

$$
\text { رئيس الحكومة. }
$$

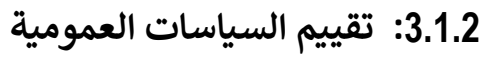

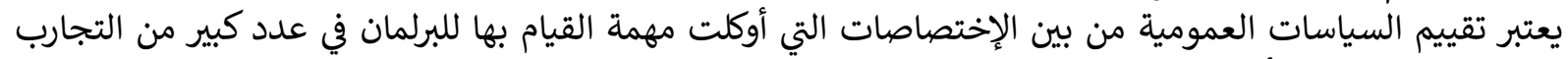

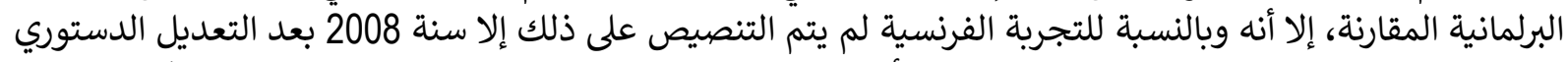

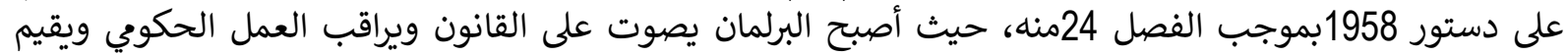

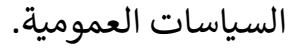

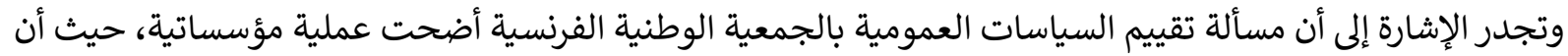

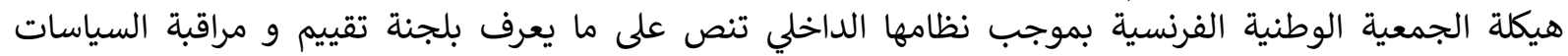

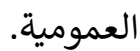

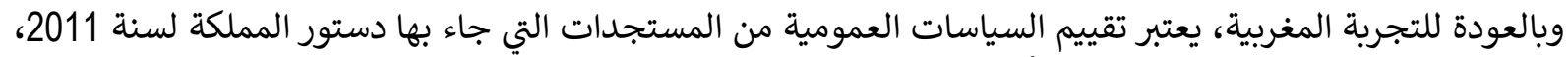

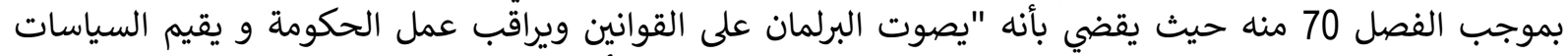

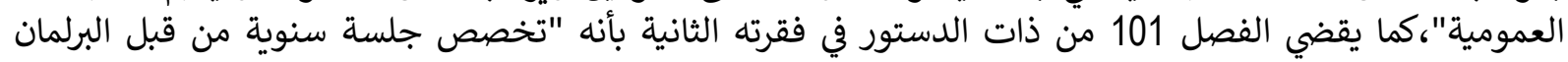

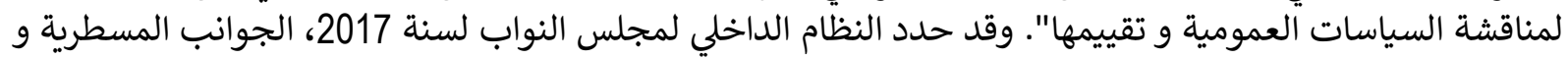

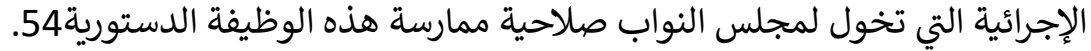

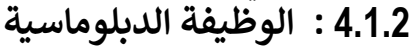

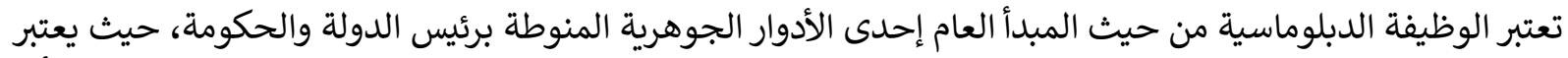

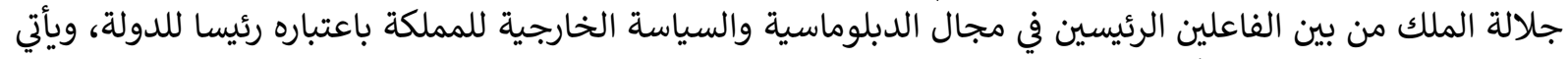
بعده الفاعلون الآخرون كالحكومة والبرن البرلمان.

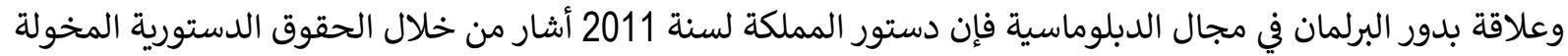

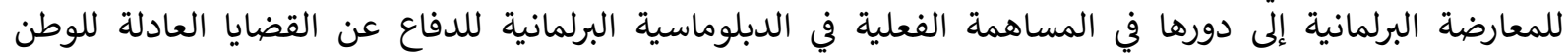

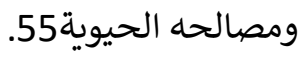

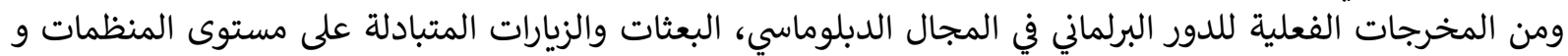

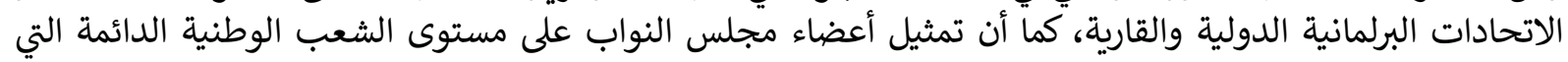

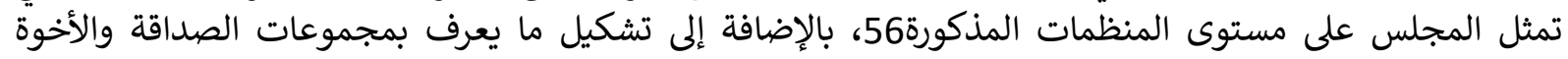

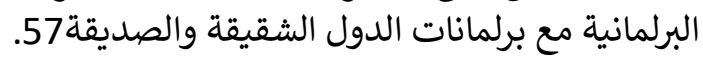

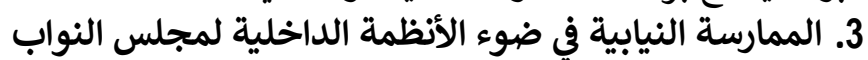

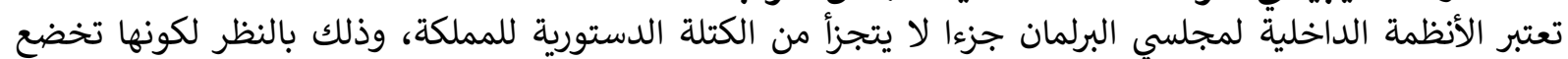

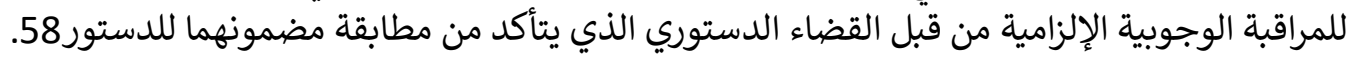

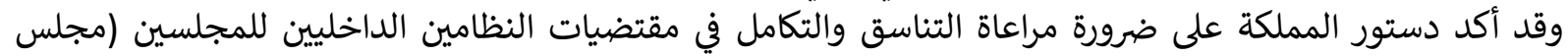

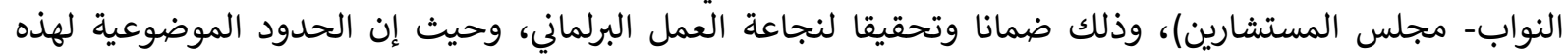

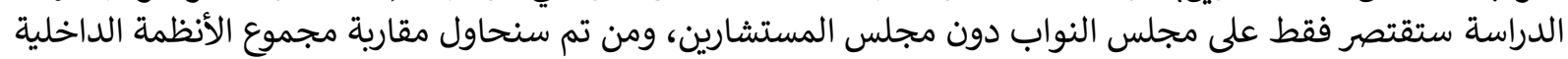

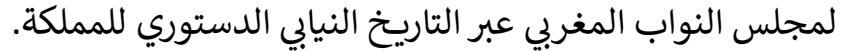

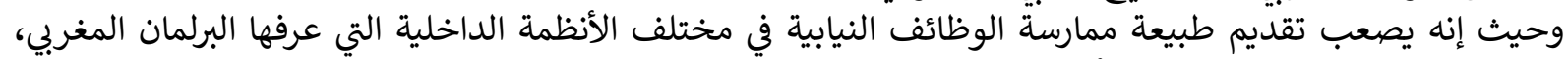

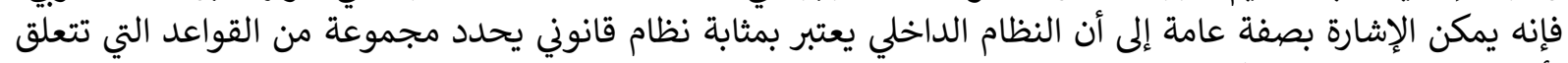

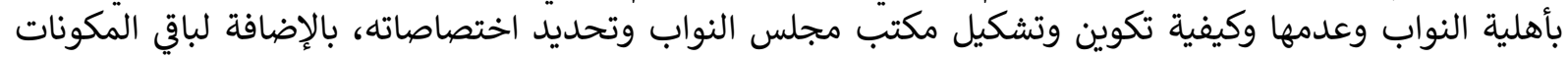

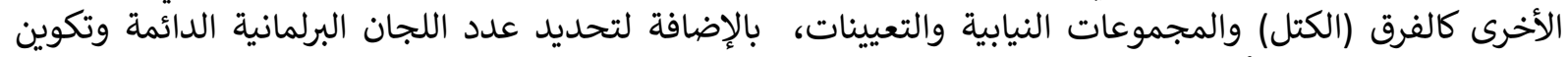

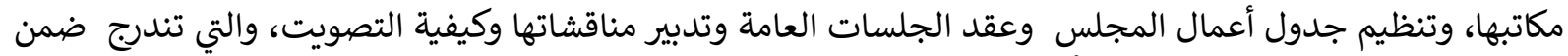

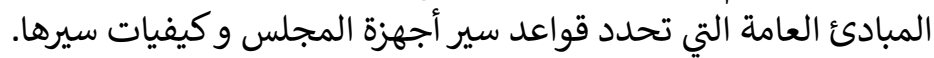

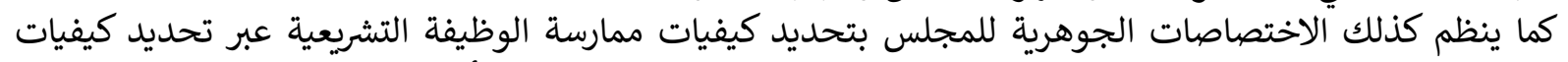

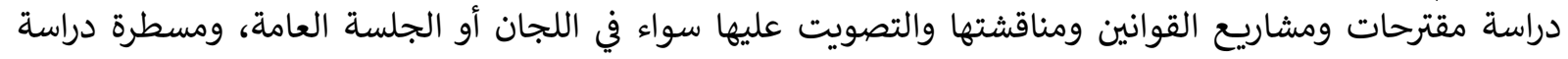


ومناقشة قانون المالية والتصويت عليه...، وكذا العلاقة مع الغرفة الثانية بالبرلمان، بالإضافة إلى تنظيم العلاقة مابين

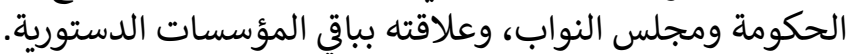

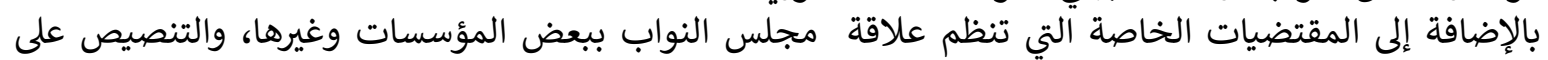

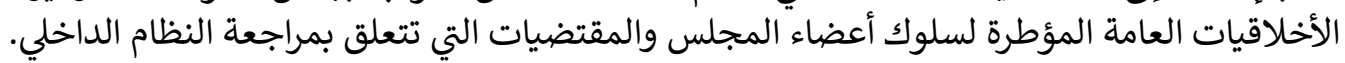

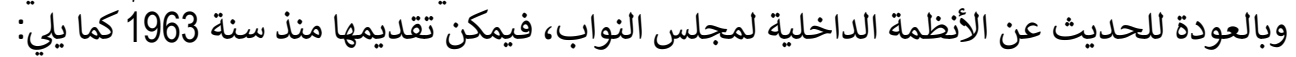

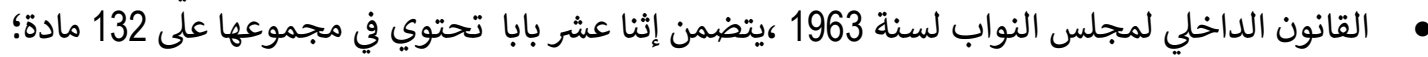

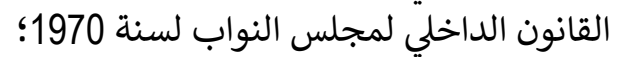
• القانون الداخلي لمجلس النواب المجلي لمجادق النواب عليه في دورة أكتوبر 1977، يحتوي في مجموعه على 125 مادة؛

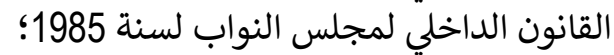

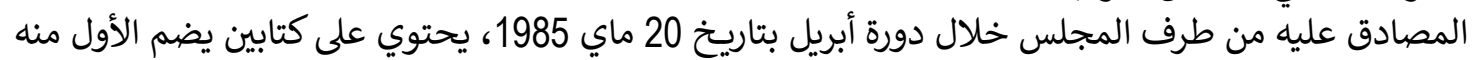

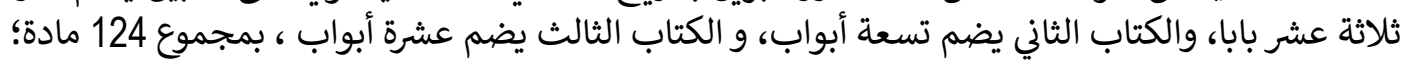

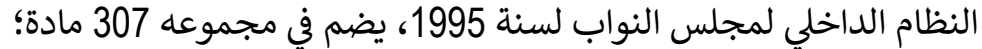
النظام الداخلي لمجلس النواب لسنة 2004، كما صأدق عليه مجليه مجلس النواب لنواب في جلسة 29 يناير 2004، يتضمن في مجموعه النظام الني 180 مادة؛

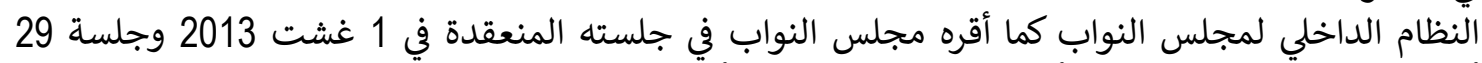

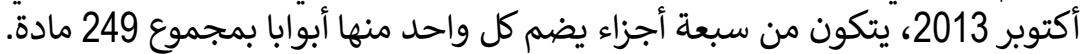

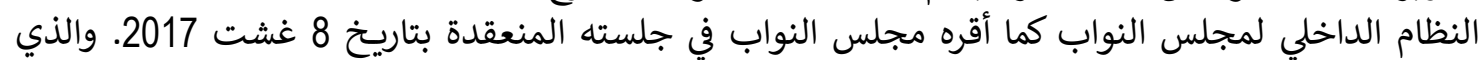

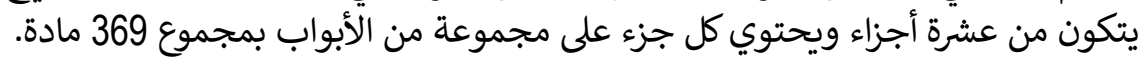

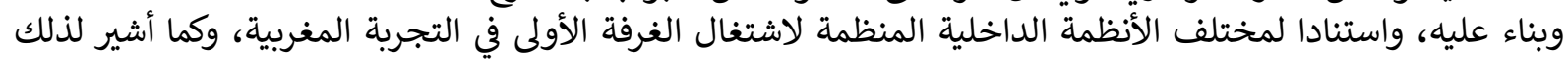

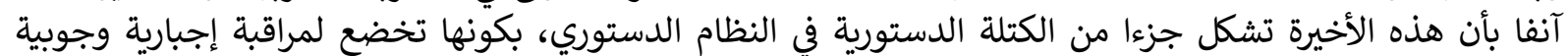

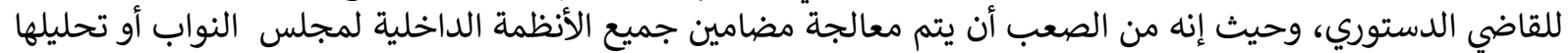

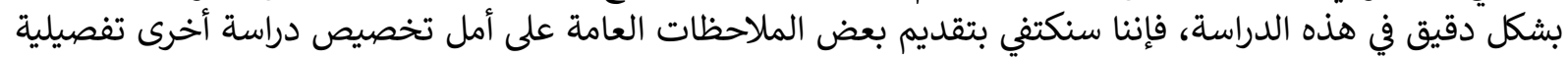

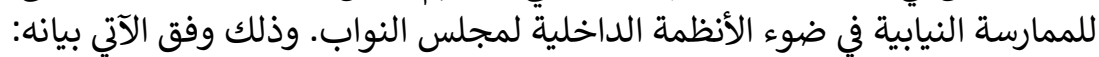

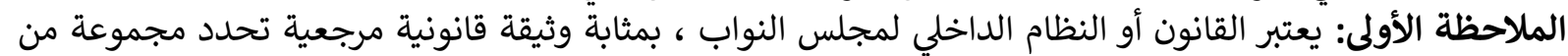

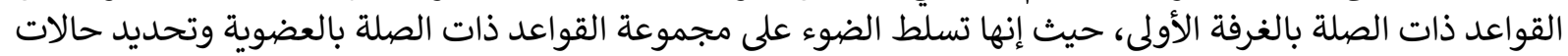

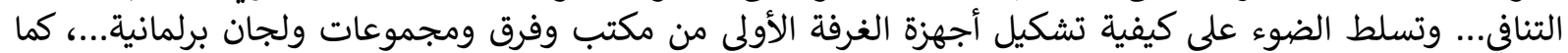

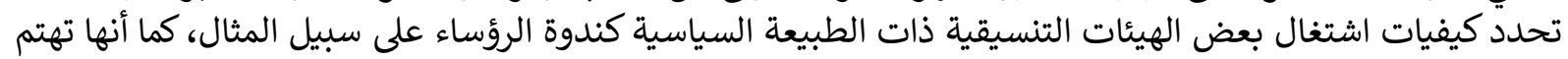

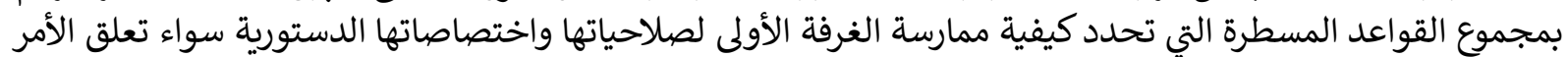

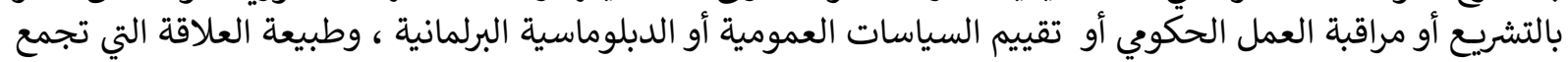

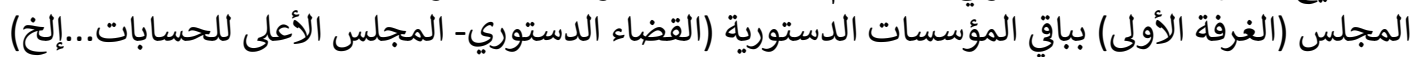

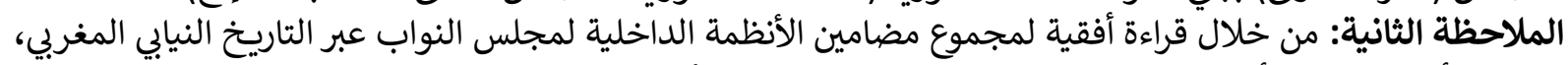

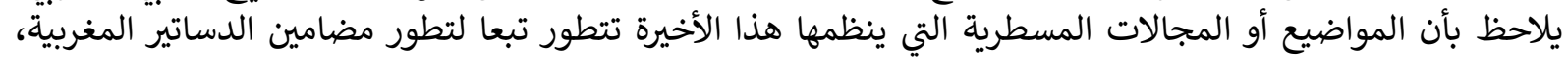

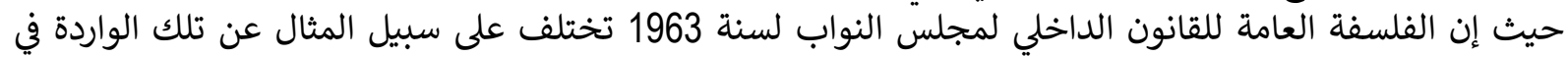
مضمون النظام الداخلي لسنة 2017.

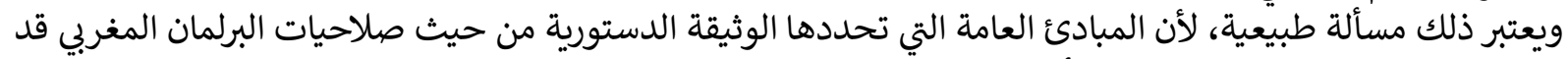

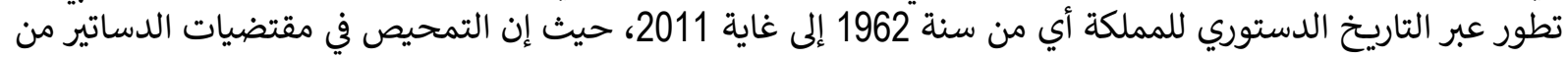

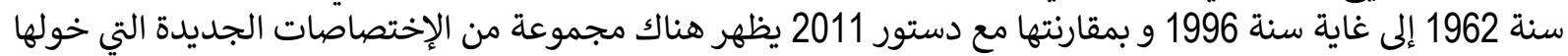

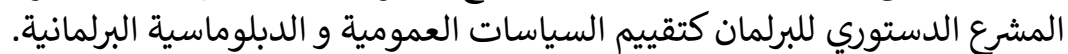

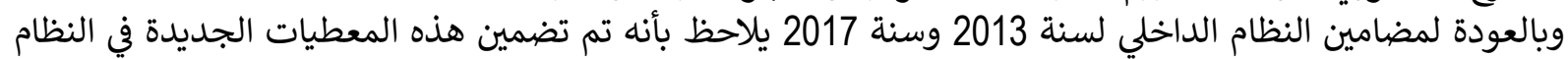

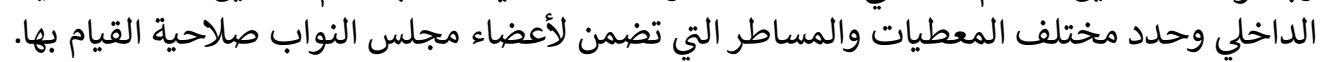
خلاصة تركيبية

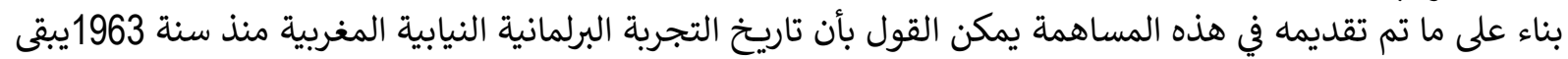

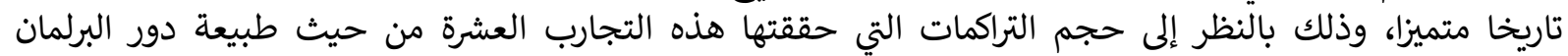

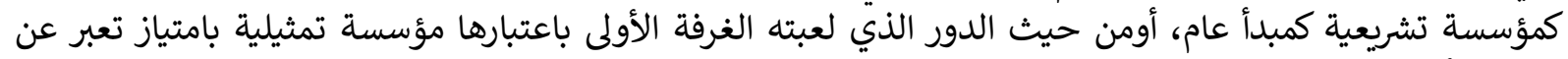

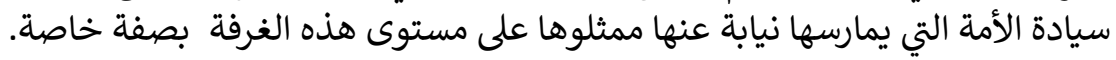




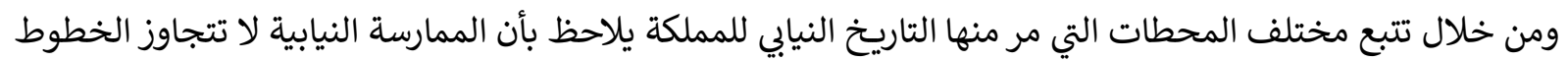

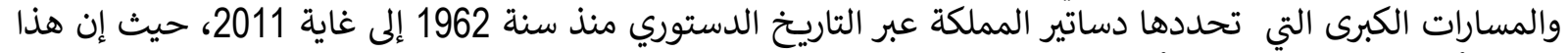

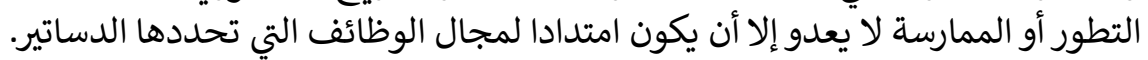

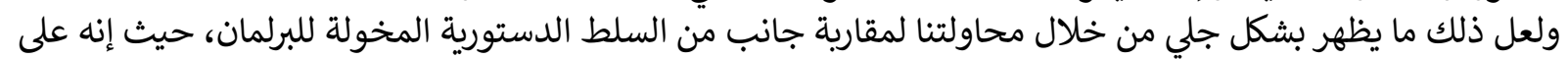

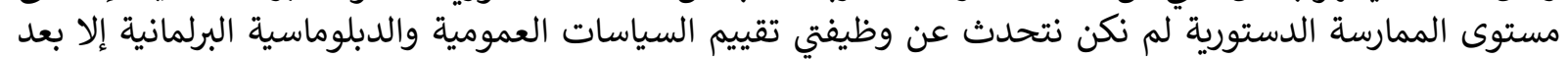

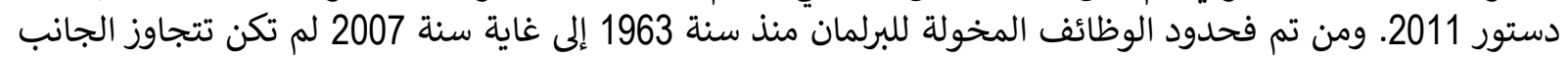

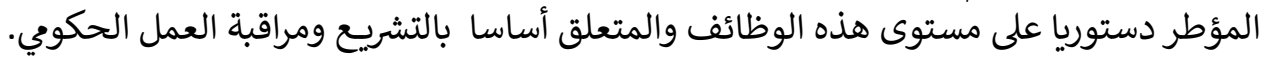

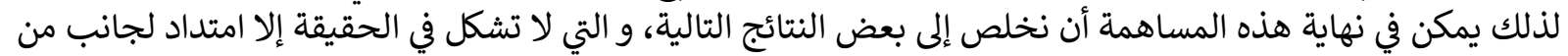

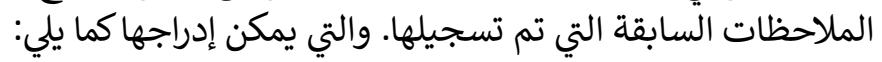

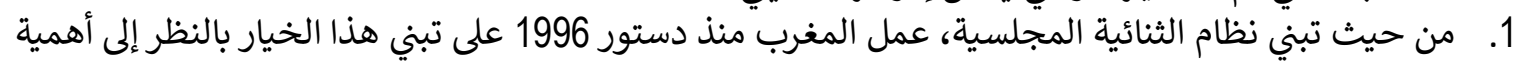

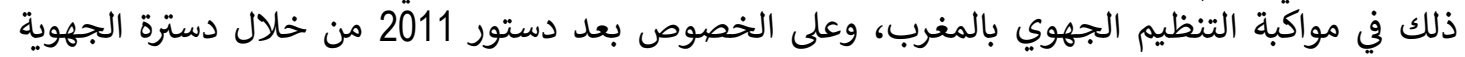

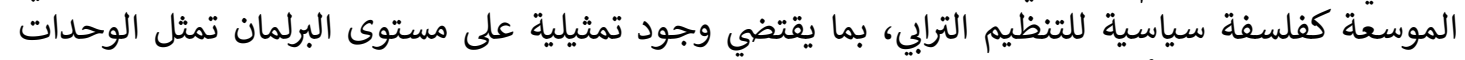

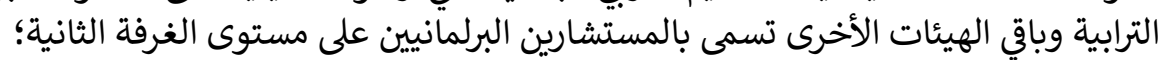

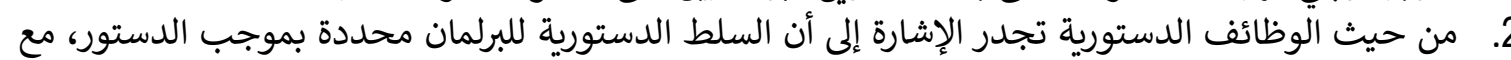

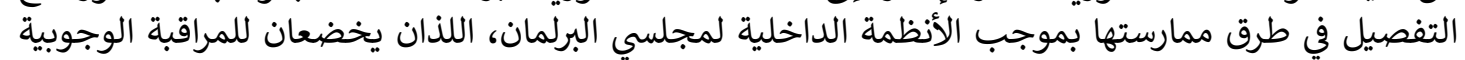

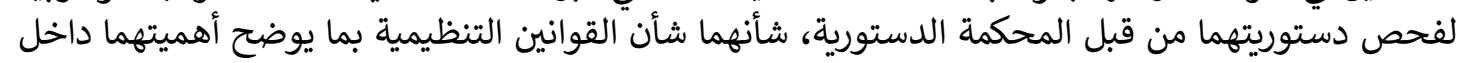

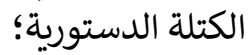

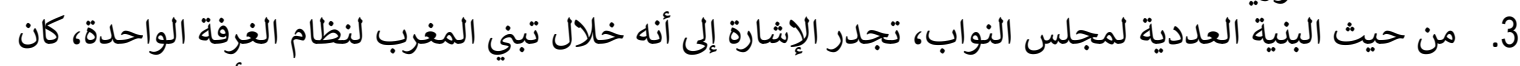

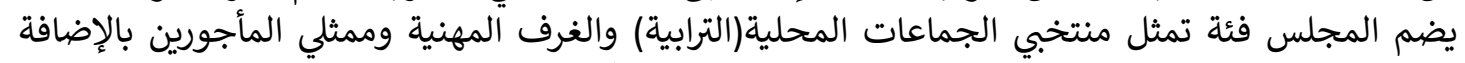

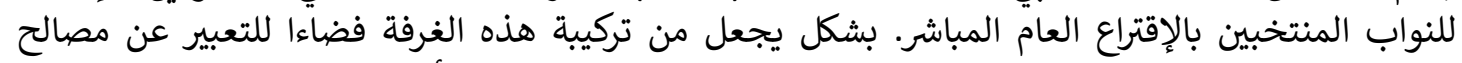

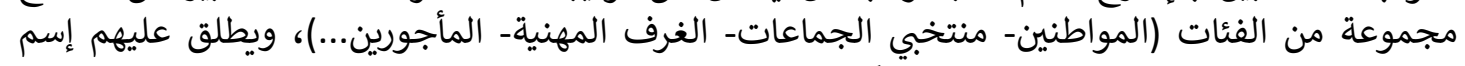

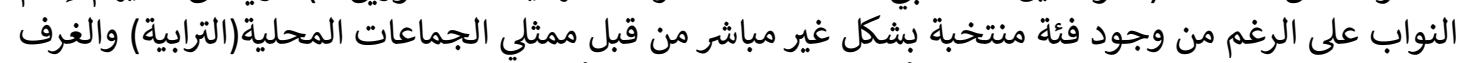

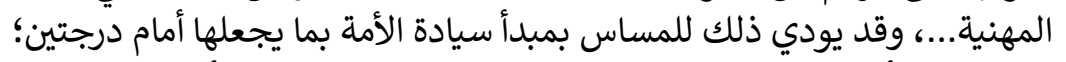

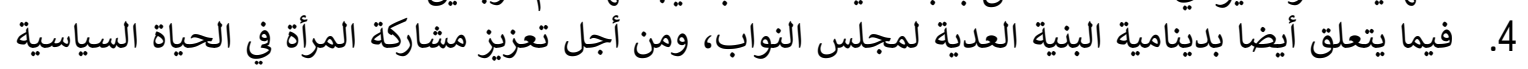

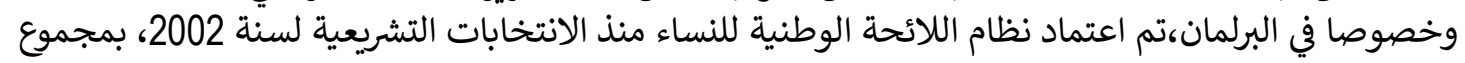

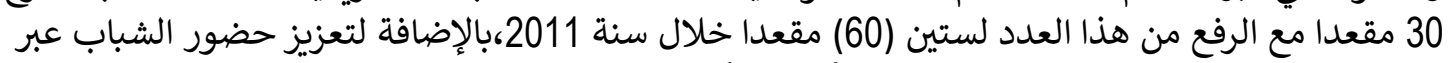

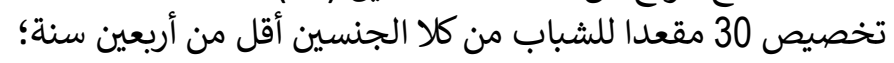

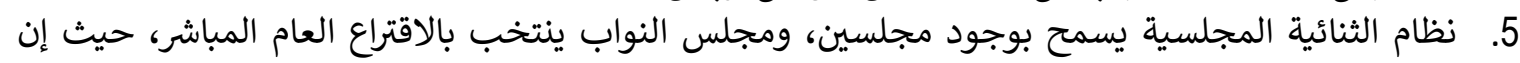

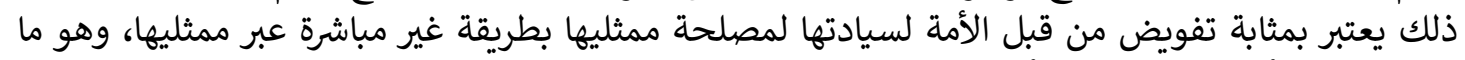

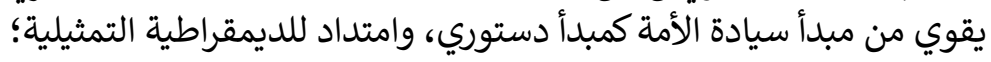

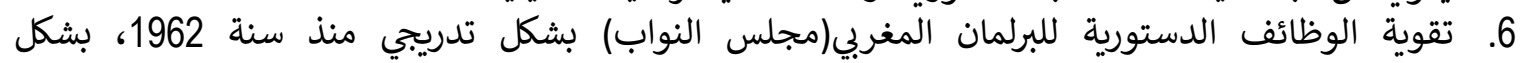

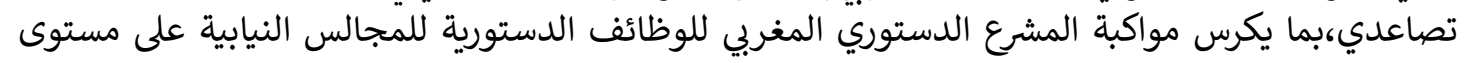

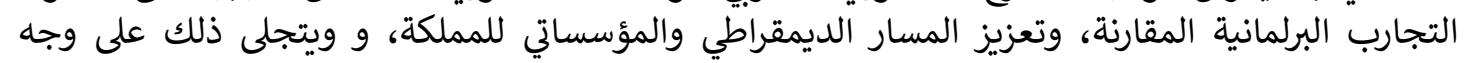
الخصوص في دستور 2011.

- دسائمة المراجع المعتمدة:
ظهير شريف رقم 1.63 .118 بشأن القانون التنظيمي لانتخاب أعضاء مجلس النواب، الجريدة الرسمية عدد 2033 مكرر

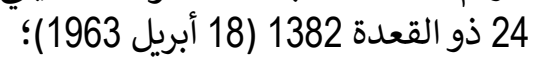


ظهير شريف رقم 1.70 .206 بتاريخ 27 جمادى الأولى 1390 (31 يوليوز 1970) بمثابة القانون التنظيمي المتعلق بتأليف مجلس النواب و انتخاب أعضائه؛

ظهير شريف رقم 177.177 بتاريخ 20 جمادى الأولى 1397(9 مايو 1977) بمثابة القانون التنظيمي المتعلق بتأليف مجلس النواب و انتخاب أعضائه؛

ظهير شريف رقم 1.97 .185 صادر في فاتح جمادى الأولى 1418 (4 سبتمبر 1997) بتنفيذ القانون التنظيمي رقم 31.97 المتعلق بمجلس النواب؛

ظهير شريف رقم 1.02 .187 صادر في 21 من ربيع الآخر 1423 (3 يوليو 2002) بتنفيذ القانون التنظيمي رقم 31.97 التمني 06.02

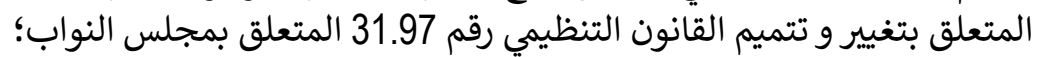

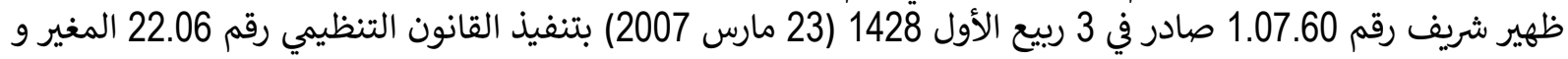

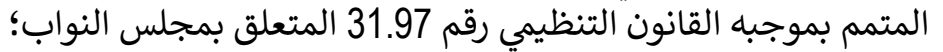

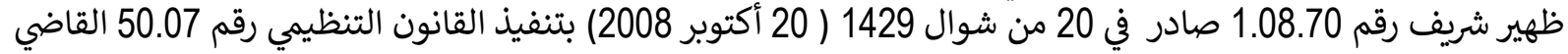

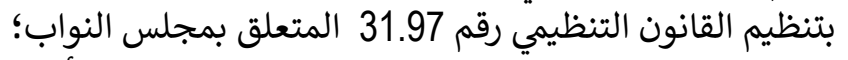

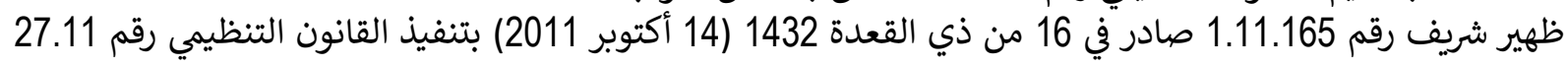
المتعلق بمجلس النواب؛

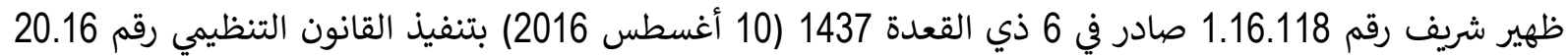
القاضي بتغيير و تتميم القانون التنظيمي رقم 27.11 المتعلق بمجلس الني النواب؛

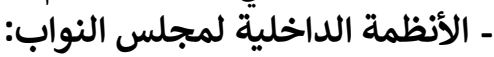

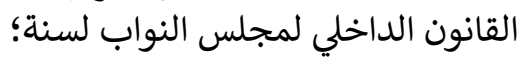

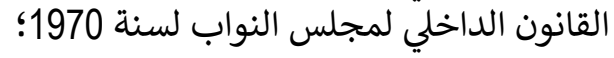

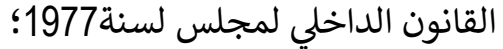

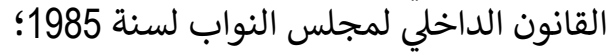

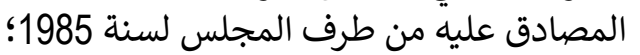

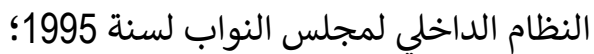

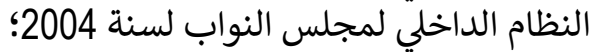

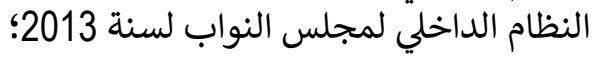

- النظام الداخلي لمجلس النواب لمجلس النواب لسنة 2017.

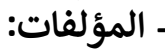

أحمد بوز،البرلمان المغربي البنية والوظائف دراسة في القانون البرلماني المغربي، المجلة المغربية للعلوم السياسية و

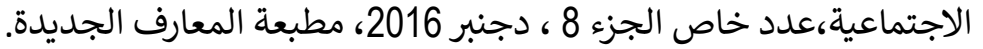

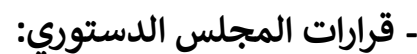

قرار المجلس الدستوري رقم 966/15 بتاريخ 30 يونيو 2015.

الهوامش

i ت تختلف التسميات التي تطلق على المجالس النيابية حسب التجارب المقارنة:

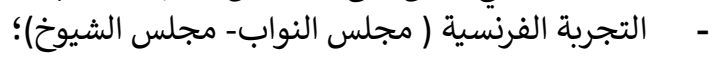

-

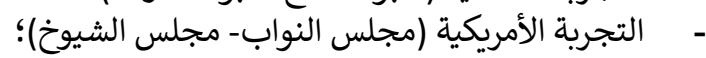

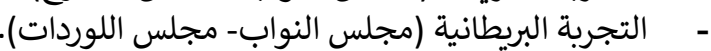

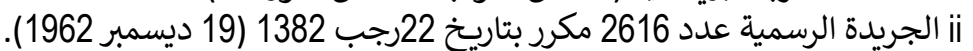

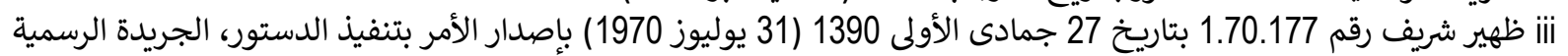

عدد 313 مكرر بتاريخ 28 جمادى الأولى 1390 نايخ 1390 (فاتح أغسطس 1970 1970).

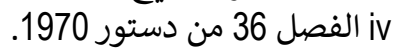

vهير شريف رقم

3098 بتاريخ 28 من محرم 1392 (15 مارس 1972) 
عادير شريف رقم 16 نو 1.92 .155 صادر في 11 من ربيع الآخر 1413 ( 14 أكتوبر 1992) بتنفيذ نص مراجعة الدستور، الجريدة الرسمية

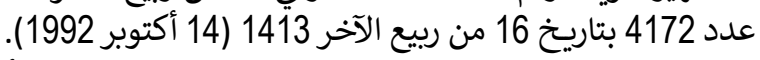
vii

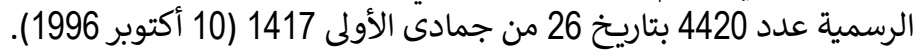

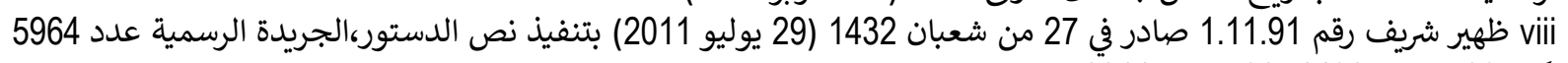

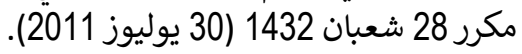
الفصل 37 من دستور 36 دان 3962 / الفصل 36 من من دستور 1970 / / الفصل 36 من دستور 1972 / الفصل 36 من دستور 1992 /

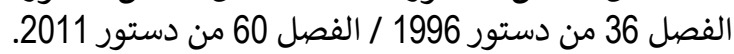

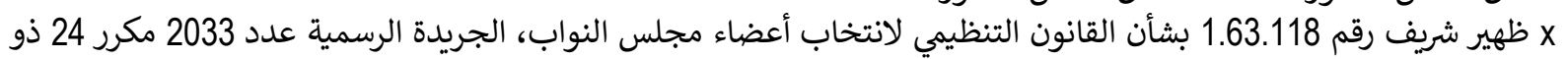

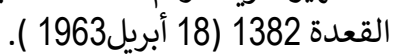

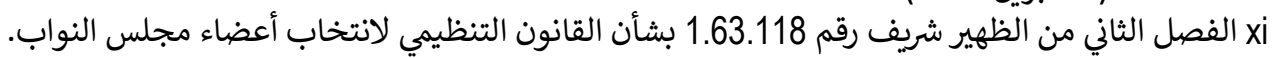

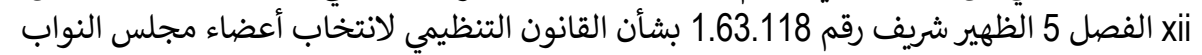

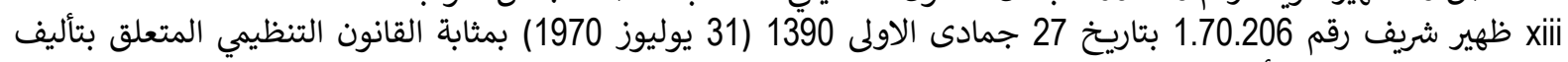

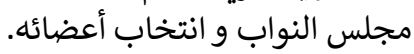
الفصل الأول من الظهير شريف رقم 1.70 .206 بتاريخ 27 جمادى الاولى 1390 (31 يوليوز 1970) بمثابة القانون التنظيمي

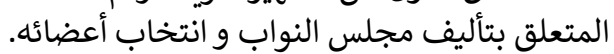

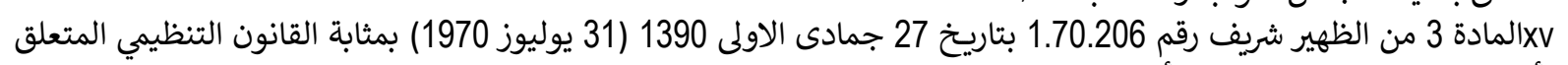

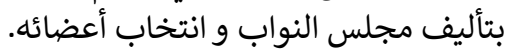

xvi الفصل 7 من الظهير شريف رقم 1.70 .206 بتاريخ 27 جمادى الاولى 1390 (31 يوليوز 1970) بمثابة القانون التنظيمي المتعلق بتأليف مجلس النواب و النت انتخاب أعضائه. xvii

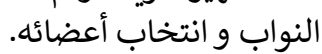
xviii بتأليف مجلس النواب و النتخاب أعضائه.

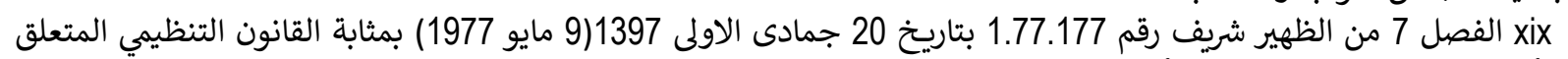

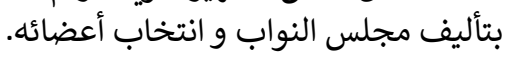

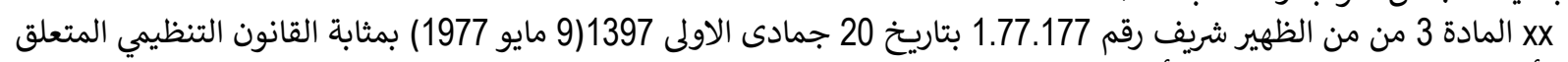

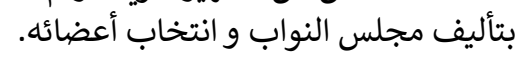

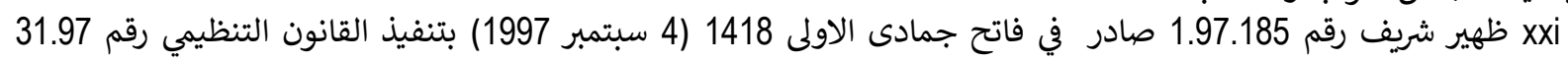

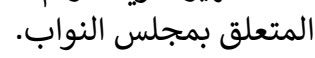
xxii المادة 1 من القانون التنظيمي رقم 4 من النظم 31.97 يتعلق بمجلس النواب.

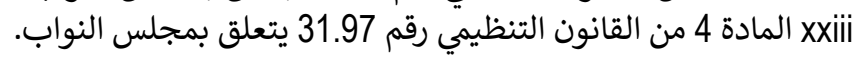
xxiv الفصل 37 من دستور xxili

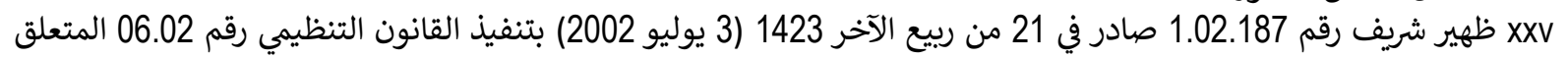

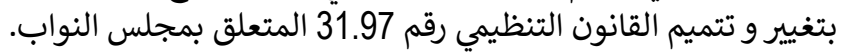

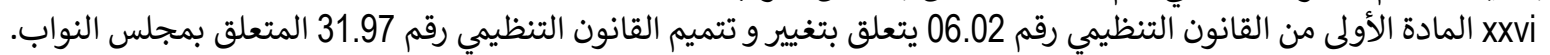
المهير شريف رقم xxvii

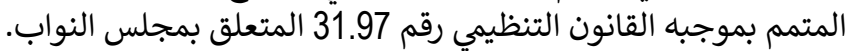

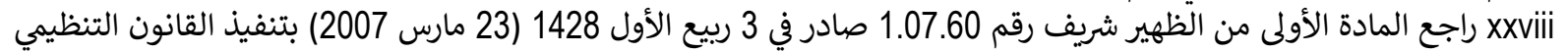

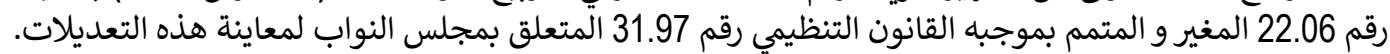
xxix الفصل 37 من دستور 1996. ظهير شريف رقم 1.08 .70 صادر في 20 من شوال 1429 ( 140 ( 20 أكتوبر 2008) بتنفيذ القانون التنظيمي رقم 50.07 القاضي

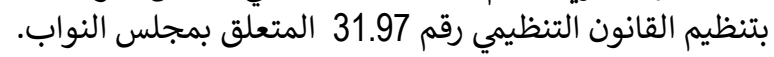
xxxi

المتعير شريف رxxii

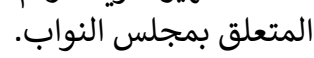
xxxiii المادة الأولى من النقابن التون التنظيمي رقم 27.11 يتعلق بمجلس النواب. 
المادة 4 من القانون التنظيمي رقم 27.11 يتعلق بمجلس النواب. ومنه فإن السن الذي أصبح محددا هو سن الرشد

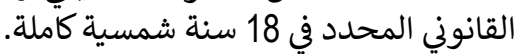

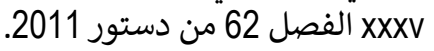
بتغير xxvi بتغيير و تتميم القانون التنظيمي رقم Xيمxنii

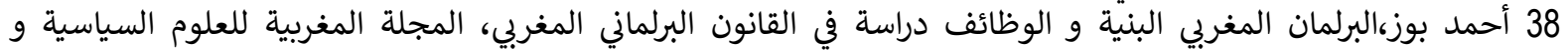

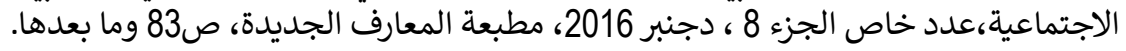

- 2 - 2 - الفصل 48 من دستور 1962 - الفصل 45 من دستور 48 من دستور 1970 - الفصل 45 من دستور 45 من دستور 1972 - الفصل 45 من دستور 1992 - الفصن دستور - 2 - الفصل 46 من دستور 1996 من دستور - 20 - الفصل 71 من دستور 2011 من دستور

40 قرار المجلس الدستوري رقم 966/15 بتاريخ 30 يونيو 2015.

42 - الفصل 43 من دستور 1962

- الفصل 42 من دستور 43 من دستور 1970

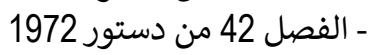

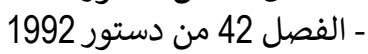

- 2 - 20 - الفصل 44 من دستور 1996 من دستور 1996

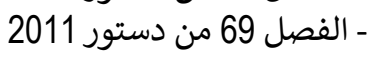

43 أحمد بوز،البرلمان المغربي البنية و الوظائف دراسة في القانون البرلماني المغربي، مرجع سابق ص 113.

44 الفصل 104 من دستور 198 من 1962

45 الفصل 98 من دستور 1970

46 الفصل 98 من دستور 198 من دستور 1972

47 الفصل 97 من دستور 103 من دستور 1992

48 المادة 103 من دستور 172

49 الفصل 172 من دستور 103 من دستور 2011 من

50 الفصل 31 من دساتير 172 من دستو 1962-1970-1972-1992-1996. 51 الفصل 59 من دستور 51 من 1962 / الفصل 55 من من دستور 56 من 1970 / 1970 / الفصل 55 من دستور 1972

52 الفصل 55 من دستور 51 من دستور 1992 / الفصل 56 من دستور 1956 من دستور

53 الفصل 10 من دستور 55 من دستور 2011.

54 الباب السابع من النظام الداخلي لمجلس النواب من دمن المواد 2011 المن 287 إلى 293.

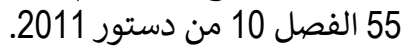

56 المادة 298 من النظام الداخلي لمجلس النظ 303 من النواب

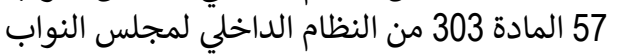

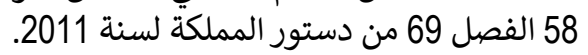

